Utah State University

DigitalCommons@USU

\title{
Expressive Writing and Marital Satisfaction: A Writing Sample
} Analysis

Rachel B. Williams

Utah State University

Follow this and additional works at: https://digitalcommons.usu.edu/etd

Part of the Family, Life Course, and Society Commons

\section{Recommended Citation}

Williams, Rachel B., "Expressive Writing and Marital Satisfaction: A Writing Sample Analysis" (2014). All

Graduate Theses and Dissertations. 4012.

https://digitalcommons.usu.edu/etd/4012

This Thesis is brought to you for free and open access by the Graduate Studies at DigitalCommons@USU. It has been accepted for inclusion in All Graduate Theses and Dissertations by an authorized administrator of DigitalCommons@USU. For more information, please contact digitalcommons@usu.edu.

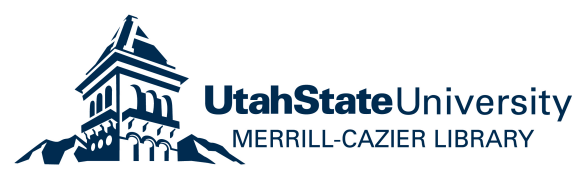


EXPRESSIVE WRITING AND MARITAL SATISFACTION:

A WRITING SAMPLE ANALYSIS

by

Rachel B. Williams

A thesis submitted in partial fulfillment

of the requirements for the degree

of

MASTER OF SCIENCE

in

Family, Consumer, and Human Development

Approved:

Scot M. Allgood

Major Professor

Ryan B. Seedall

Committee Member
Elizabeth B. Fauth

Committee Member

Mark McLellan

Vice President for Research and

Dean of the School of Graduate Studies

UTAH STATE UNIVERSITY

Logan, Utah

2014 
Copyright (C) Rachel B. Williams 2014

All Rights Reserved 


\author{
ABSTRACT \\ by \\ Rachel B. Williams, Master of Science \\ Utah State University, 2014 \\ Major Professor: Dr. Scot M. Allgood \\ Department: Family, Consumer, and Human Development
}

Expressive Writing and Marital Satisfaction: A Writing Sample Analysis

Writing provides a symbolic way of expressing thoughts, feelings, and emotions. There is little research that includes marital relationships and expressive writing and no known research that includes marital relationships and writing analyses. The purpose of this study is to enhance understanding of the relationship between writing samples and marital satisfaction. Specifically, the purpose of this study is to better understand how the use of personal pronouns and affective language in writing samples is associated with marital satisfaction. Data were gathered from 79 married couples who completed a couple satisfaction questionnaire and participated in a writing exercise about their relationship. To answer the research questions, this study used a dyadic analysis model called the actor-partner interdependence model. Findings revealed that those who used more first person plural pronouns in their writing were likely to report greater satisfaction in their relationship. However, there was no relationship between first person singular pronouns and marital satisfaction. Findings about positive affective language indicate that those who used more positive language in their writing reported greater marital 
satisfaction. Also, those whose partners used more positive language in their writing were likely to report greater marital satisfaction. Although negative emotion language was not significant, it approached significance, $p=.06$, and so the question of an effect for specific types of negative emotion arose. Findings indicated that those who used more angry language in their writing reported lower marital satisfaction. Implications for future research and applied interventions are discussed. 


\title{
PUBLIC ABSTRACT
}

Expressive Writing and Marital Satisfaction: A Writing Sample Analysis

\author{
Rachel B. Williams
}

The mode of expression used by individuals, in written or spoken word, offers insight into one's cognitive and emotional processes. Over the past 25 years expressive writing has become an interest to researchers, therapists, and the public. Writing provides a symbolic way of expressing thoughts, feelings, and emotions. Analytical programs provide a way to study the structure and content of written communication. There is little research that includes marital relationships and expressive writing and no known research that includes marital relationships and writing analyses. In relationships, meanings are created to help make sense of situations and interactions. Symbols also include the process of evaluating relationships.

The present study uses the Linguistic Inquire and Word Count (LIWC) to analyze the writing samples from participants and the Couples Satisfaction Index (CSI) to measure relationship satisfaction. To more fully understand the relationship between writing and couple satisfaction, this study focused on married couples. This study used a dyadic analysis approach so that partner effects could be analyzed.

This study had two main goals: (1) to examine the relationship between first person pronoun use (singular and plural) and marital satisfaction, and (2) to examine the relationship between affective language use (positive and negative) and marital 
satisfaction. Each of these goals also included exploring possible sex and length of marriage differences.

The results from this study indicate that individuals who use more first person plural pronouns (e.g., we) are more likely to report higher marital satisfaction. This indicates that individual perceptions of couple togetherness are related to higher marital satisfaction. Results also indicate that individuals who use more positive affective language are more likely to report higher marital satisfaction. Also, individuals whose partners use more positive affective language are more likely to report higher marital satisfaction. This suggests that positive affect in relationships is linked to higher satisfaction for both spouses. Although negative affective language was not related to marital satisfaction, if individuals used anger language it was negatively associated with marital satisfaction. This reveals the need for more research on the specific effects of anger on relationship satisfaction. Examining relationships from this new perspective may have valuable implications for couple therapy, interventions, and future research. 


\section{ACKNOWLEDGMENTS}

I first would like to thank Dr. Scot M. Allgood for giving me so much of his time. He was patient with me as I learned the research process. He was encouraging and fun along the way. He worked hard so I could finish and is an incredible mentor.

I would also like to thank my great committee members for their help. Dr. Ryan Seedall spent numerous hours with me working on the data analysis and results. He was extremely patient and taught me a lot about statistics. He went above and beyond to help me through the process. Dr. Beth Fauth consistently offered encouragement and excitement about the project. She would help me feel better every time I felt overwhelmed or like the project might not ever end.

I would like to thank my friends, colleagues, and professors in the department who always believed in me and kept me going. I looked to them for help and support. They were a great building block and foundation along the way.

I am especially indebted to my family for their continued inquiries about my schooling that turned into countless hours of listening to where I was in the process. My parents, siblings, and in-laws were all cheering me along. Last but not least, I would like to thank my best friend and husband for seeing me through all the ups and downs of this project. He was encouraging and motivating throughout it all...even when I wanted to quit. His outpouring of love and praise were needed every step of the way. He never failed to believe in me. I COULD NOT have done it without him. And thanks to our little Maxwell. He gave me great motivation to finish within my targeted timeline. :) 


\section{CONTENTS}

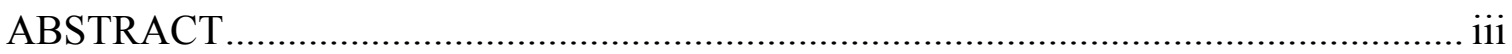

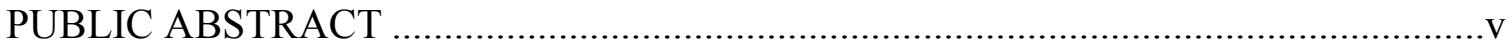

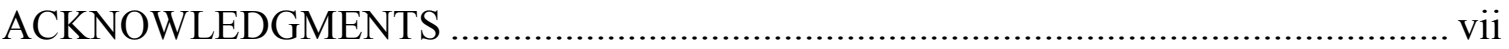

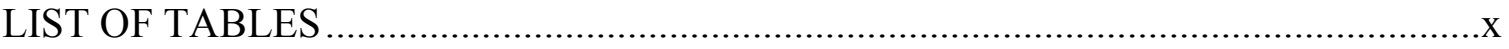

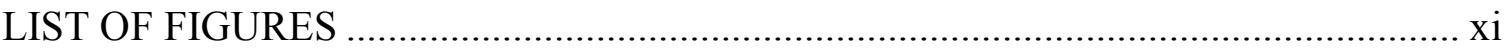

\section{CHAPTER}

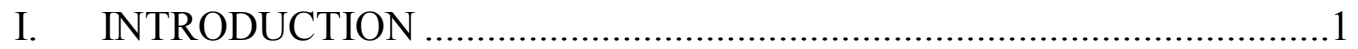

Expressive Writing................................................................... 1

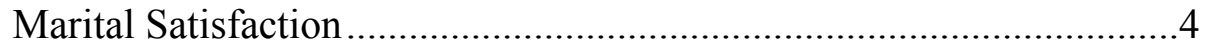

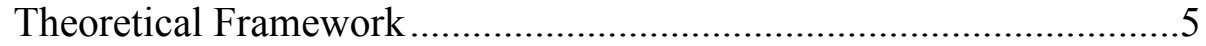

Purpose of the Study ................................................................. 7

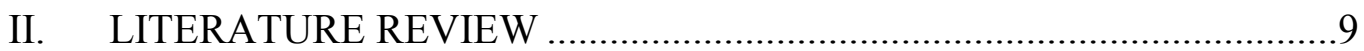

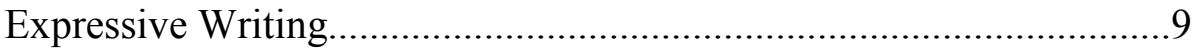

Expressive Writing Interventions ................................................10

Writing Analysis Programs........................................................16

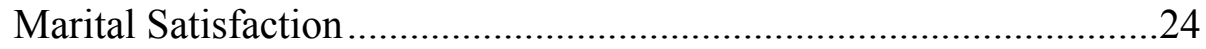

Factors Influencing Marital Satisfaction.......................................25

Conclusions and Research Questions ................................................31

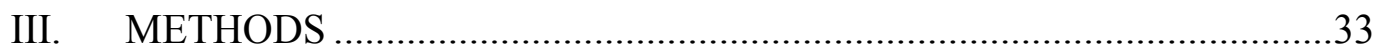

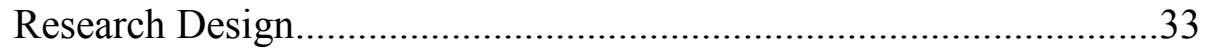

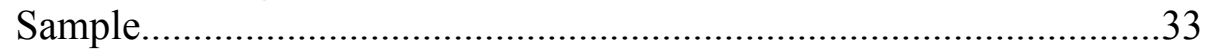

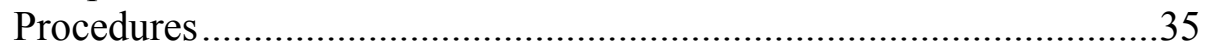

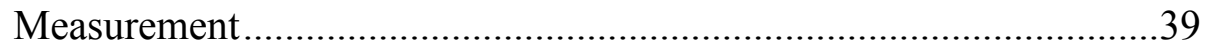

Data Analytic Strategy and Approach .............................................41

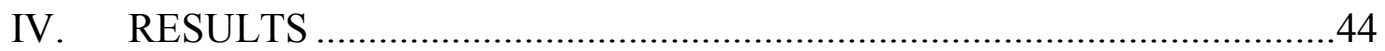

Analysis Model Decision Process..................................................45

Research Question 1: What Is the Relationship Between Personal Pronouns and Marital Satisfaction? 
Research Question 2: What Is the Relationship Between Affective Language Use and Marital Satisfaction? .......................................48

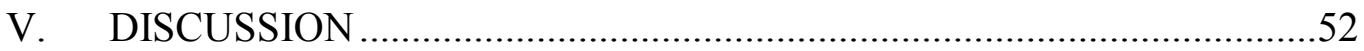

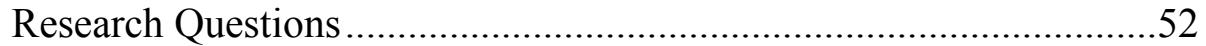

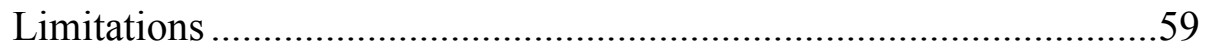

Implications and Future Research..............................................59

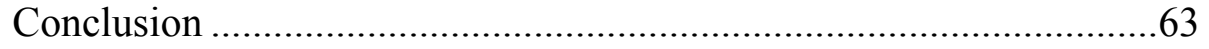

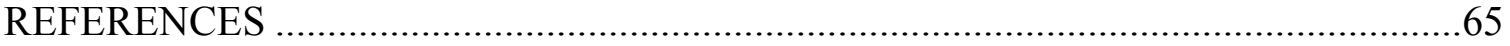

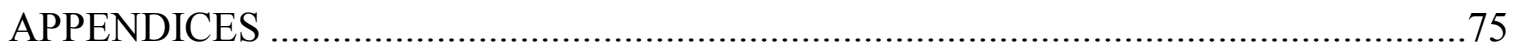

Appendix A: Letter of Information............................................ 76

Appendix B: Information Survey...................................................79 


\section{LIST OF TABLES}

Table $\quad$ Page

1 Summary of Demographic Characteristics of the Sample ......................................34

2 Summary of Categorical Characteristics of the Sample ……………………..........36

3 LIWC Category Examples ............................................................................

4 Bivariate Correlations of Demographic and Covariate Variables by Sex

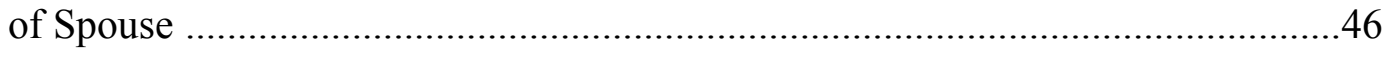

$5 \quad$ Model for First Person Pronouns and Marital Satisfaction....................................48

$6 \quad$ Model for Affective Language and Marital Satisfaction .....................................49

$7 \quad$ Follow-up Model for Affective Language and Marital Satisfaction .....................51 


\section{LIST OF FIGURES}

Figure

1 The actor-partner interdependence model ... 


\section{CHAPTER I}

\section{INTRODUCTION}

Historically, therapeutic theories propose that there are many benefits of verbal emotional expression (Crain, 2011). Breuer and Freud (1966) believed that suppressing emotional experiences could have adverse physical and mental consequences. They further explained that by bringing the original thoughts and feelings from the unconscious to conscious, the effects of trauma would be released (Breuer \& Freud, 1966). The components of expressing emotions, thoughts, and feelings form a large part of the foundation of psychotherapy (Esterling, Antoni, Fletcher, Margulies, \& Schneiderman, 1994).

Therapy uses language and words as symbols to define emotions. The psychotherapeutic assumption that expression relieves difficulties that accompany traumatic experiences has influenced the use of writing as a therapeutic mode of expression (Pennebaker, 1997). Although psychotherapy focuses mainly on verbal expressions, writing is also a method of expression that influences feelings, thoughts, and actions in individual lives and societies as a whole (Lepore \& Smyth, 2002).

\section{Expressive Writing}

The mode of expression used by individuals, in written or spoken word, offers insight into one's cognitive and emotional processes (Pennebaker, Chung, Ireland, Gonzales, \& Booth, 2007). Although verbal expression and writing expression have both been used as effective therapeutic tools, writing offers a few specific advantages to some 
people. Expressive writing offers an innovative way to gain insights without much cost and with freedom from location limitations. Some individuals may prefer writing as it limits social judgment (Lepore \& Smyth, 2002). These advantages have influenced an interest about expressive writing for researchers, therapists, and the public (Lepore \& Smyth, 2002).

Pioneering writing interventions offer revealing and moving insights into the personal accounts of stressful experiences (Lepore \& Smyth, 2002). The basic expressive writing intervention, as proposed by Pennebaker (1997), entails people writing about thoughts and feelings related to a stressful event for 15-30 minutes several times.

Expressive writing interventions have been related to enhanced life in many areas (Pennebaker, 1997). These interventions have been effective and beneficial in areas including physical health (Burton \& King, 2004; Hevey, Wilczkiwicz, \& Horgan, 2012; Pennebaker, 1997), cognitive functioning (Burns \& Friedman, 2012; Lumley \& Provenzano, 2003), emotional health (Bhullar, Schutte, \& Malouff, 2011; Burton \& King, 2004; O’Connor et al., 2011), and social relationships (Baddeley \& Pennebaker, 2011; Lepore \& Greenberg, 2002; Slatcher \& Pennebaker, 2006).

As different benefits of expressive writing have been explored, questions about how, where, and why these benefits take place have come to the forefront. Writing analysis programs have been developed to try and answer these questions. These analytical programs provide a way to study the structure and content of communication (Pennebaker et al., 2007). 
Through the use of text analyses, researchers have found certain writing characteristics that are associated with greater benefit for participants in a variety of studies (Pennebaker et al., 2007). Characteristics such as amounts of positive and negative emotion words (Pennebaker, Mayne, \& Francis, 1997), use of pronouns (Campbell \& Pennebaker, 2003), and cognitive and emotional processing (Warner et al., 2006) are indicators that the author of the expressive writing will experience greater benefit compared to other participants. Specifically, pronoun change (e.g., changes in first and second person pronouns) across writing samples are related to greater health benefits (Campbell \& Pennebaker, 2003).

Why are there benefits for participants who write about emotional experiences? Although these questions cannot be answered for certain, there are speculations about the benefits and insight gained through writing. Campbell and Pennebaker (2003) have proposed that writing is more beneficial for individuals whose writing changes across time. This may reflect benefits of changes in perspectives and process. Similarly, Warner and colleagues (2006) conclude that writing improves emotional functioning (improved positive affect) and behavioral functioning (ability to perform routine physical behaviors like walking upstairs, etc.), especially if the writing reflects cognitive and emotional processing. Despite not knowing the actual mechanism, the benefits of expressive writing are clear.

There is little research that includes marital relationships and expressive writing interventions (Baddeley \& Pennebaker, 2011; Jordan, 1998) and no research that includes marital relationships and writing analyses. Writing analysis studies that include married 
couple writing samples could offer insight into relationship satisfaction that cannot be found by expressive writing interventions. The writing analysis provides more depth and understanding into some of the mechanics behind relationship satisfaction.

\section{Marital Satisfaction}

Marriage and marital satisfaction are often major topics for professionals in the field of family science, education, and practice (Fincham \& Beach, 2010). Researchers and practitioners aim to find, create, and validate effective interventions. Although the dynamics and configurations of marriage are changing, there continues to be vast research on marital satisfaction (Fincham \& Beach, 2010).

There are factors that are related to marital satisfaction that could be reflected through and detected in writing. The use of pronouns influences perceptions of relationships (Fitzsimons \& Kay, 2004). The way individuals use first person singular (I, me) and first person plural (we, us) pronouns is connected with commitment in a relationship (Agnew, Van Lange, Rusbult, \& Langston, 1998).

Positive and negative affect also play a part in relationship satisfaction (Fincham \& Beach, 2010; Mattson, Frame, \& Johnson, 2011). Positive affect can moderate the effects of low problem-solving skills in marriages (Bradbury \& Karney, 2004; Fincham \& Beach, 2010). Low levels of positive affect in marriages are also related to declines in marital satisfaction (Fincham \& Beach, 2010). 


\section{Theoretical Framework}

Symbolic interaction theory is one theory that may help to understand the premise of this research. Humans use symbols and live in a symbolic world. For example, encouragement of verbal expressions about emotional topics, which are symbolic in nature, is a widely used therapeutic tool. Emotional awareness is often a principal goal in individual or couple therapy (Lepore \& Smyth, 2002). Expressions in words about a certain experience or topic opens access to information about how to adapt and act. Making sense of what emotions mean and what to do accordingly is an organizational process. Humans have the tendency to avoid strong emotions, especially when painful (Greenberg \& Pascual-Leone, 2006). Emotional avoidance can lead to dysfunctional behavior. Attending to the emotional experience helps individuals function better in many areas (Breuer \& Freud, 1966; Greenberg \& Pascual-Leone, 2006).

Symbolic interaction framework helps explain this phenomenon. Symbolic interaction theory explains that the world is symbolic and humans use symbols to understand the world and human behavior. Language offers a symbolic way to organize perceptions and thoughts. The way humans think about and perceive symbols is arranged through language. Language provides the structure for interpreting, understanding, and expressing meaning. The organization of symbols about a given situation explains the problems, actions, and solutions associated with the situation. The human mind allows for the acquisition, integration, and processing of information (White \& Klein, 2008). Symbolic meanings are learned and socially constructed (Vernon, 1974). 
This study used symbolic interaction framework as the foundation because it gives insight to the connection between writing and marital satisfaction. Traditionally, symbolic interactionism views each person as an individual who then comes together with others to form the order of the society or the couple in which the individual interacts (Stephen, 1984). This highlights the importance of interaction within the symbolic world individuals create. These interactions construct the meanings of symbols (Stephen, 1984). For example, the symbol of marriage holds different meanings for societies throughout the world and has held different meanings throughout history. In some societies today, marriage is a symbol of romantic love, individual choices, and preferences. In others, marriage is a symbol of political, economic, or familial choices and preferences (Miller, 2012). These societal or cultural norms influence individual definitions, beliefs, symbols, and attitudes about marriage (White \& Klein, 2008).

Symbolic interaction theory emphasizes that the interpretation and organization of events, words, and actions are important in relationships. In relationships, meanings are created to help make sense of situations and interactions (White \& Klein, 2008). Symbols also include the process of evaluating relationships. Role definitions and expectations (who does what in the relationship) play a large role in creating and sustaining happy relationships. The measurement of marital satisfaction, for example, is based on symbols, individual meaning of words, and symbolic interactions. Individuals develop the concept of who they are through social interactions and in turn, make independent assessments and value assignments of family activities (LaRosa \& Reitzes, 
1993). The words people use communicate perceptions about the social world of relationships (Fitzsimons \& Kay, 2004).

Through the study of symbols and meanings that are shared between a couple, the couples' behavior, processes, and rituals may be better understood (Stephen, 1984). A couples' reality consists of the construction of shared meanings. Like societal construction of shared meanings and definitions that are validated by interactions, couples form meanings and definitions which are often in harmony with the norms of society (Berger \& Kellner, 1994). Understanding the symbolic environment of a couple and their rituals that increase (or decrease) mutual commitment is an important concept when examining marital satisfaction (Stephen, 1984).

Writing uses language and words as symbols to express thought and feeling (Lepore \& Smyth, 2002). Through writing, one organizes thoughts and feelings associated with any given topic (Pennebaker, 1997). An individual's feelings and perceptions about a certain topic, like marriage, could be reflected through writing. It is proposed that an analysis of writing could then depict which symbols and meanings couples use that relate to marital satisfaction.

\section{Purpose of the Study}

Expressive writing interventions have been effective in improving health in many areas including physical health (Burton \& King, 2004; Hevey et al., 2012; Pennebaker, 1997), cognitive functioning (Burns \& Friedman, 2012; Lumley \& Provenzano, 2003), emotional health (Bhullar et al., 2011; Burton \& King, 2004; O’Connor et al., 2011), and 
social relationships (Baddeley \& Pennebaker, 2011; Lepore \& Greenberg, 2002; Slatcher \& Pennebaker, 2006). Writing analysis programs have provided a way to look for where and how these interventions are beneficial (Pennebaker et al., 2007). Like expressive writing interventions, the majority of expressive writing analyses have focused on individual outcomes and writing characteristics, with few studies examining couple writing samples and dyadic relationships.

While there are some studies that address how expressive writing analyses and dating relationships are related (Campbell \& Pennebaker, 2003; Lepore \& Greenberg, 2002), this association is not clear in marriages. With no research looking at expressive writing analyses and married couples, there is a need to examine the potential associations of marital satisfaction from writing samples. The effectiveness of writing analyses in relation to marital satisfaction may give grounding for relationship writing interventions and other future research.

Based on existing literature and symbolic interactionism framework, the purpose of this study was to enhance understanding of the relationship between writing samples and marital satisfaction. Specifically, the purpose of this study was to better understand how the use of pronouns (amount of first person singular and first person plural pronouns) and affect (amount of positive and negative affect language) in writing samples was associated with marital satisfaction. The potential for differing writing styles by sex of spouse and length of marriage was also explored. 


\section{CHAPTER II}

\section{LITERATURE REVIEW}

This chapter reviews the expressive writing literature, including the interventions that examine the relationship between expressive writing and situational improvements (e.g., physical health improvement). The literature that demonstrates the usefulness of writing analysis programs will also be addressed. A brief review of some of the factors that influence marital satisfaction, including factors that may be linked to writing components, will then be presented. As a result of these findings, a case is made that the use of writing samples from married couples may be associated with marital satisfaction questionnaire scores. At the conclusion of this chapter, research questions are presented.

\section{Expressive Writing}

Expressive writing, a relatively new phenomenon to research, has inspired many researchers to study the power of writing about emotional experiences (Bhullar et al., 2011; Burns \& Friedman, 2012; Burton \& King, 2004; Hevey et al., 2012; Lepore \& Greenberg, 2002; O’Connor et al., 2011; Pennebaker, 1997). Expressive writing has been shown to enhance life in many areas (Pennebaker, 1997). In most basic writing paradigm designs, participants are randomly assigned to one of two or more groups consisting of control and treatment groups. Both the control and treatment groups were asked to write for 15-20 minutes on 3-5 consecutive days. Although writing instructions vary across different studies, the treatment group was asked to write about emotional topics while the control group was directed to write about topics more superficial (daily 
activities, etc.). The outcomes for groups were then compared in respect to the dependent variable (number of doctor visits, asthma symptoms, etc.; Pennebaker, 1997). Sample sizes varied from 42 to 200 (Agnew et al., 1998; Burton \& King, 2004; Smyth, 1998) and most participants were college students (Burton \& King, 2004; Lepore \& Greenberg, 2002; O’Connor, et al., 2011; Pennebaker, 1997).

\section{Expressive Writing Interventions}

Numerous interventions using the expressive writing (EW) paradigm have been evaluated to explore the benefits for writing. The benefits of EW include physical health (Burton \& King, 2004; Hevey et al., 2012; Pennebaker, 1997), cognitive functioning (Burns \& Friedman, 2012; Lumley \& Provenzano, 2003), emotional health (Bhullar et al., 2011; Burton \& King, 2004; O’Connor et al., 2011), and social relationships (Baddeley \& Pennebaker, 2011; Lepore \& Greenberg, 2002; Slatcher \& Pennebaker, 2006).

\section{Physical Health}

The physical health characteristics explored in expressive writing interventions vary from broad to specific. General health benefits, such as lower frequency of doctor visits, have been associated with experimental groups in expressive writing interventions (Burton \& King, 2004; Pennebaker, 1997). Other research focuses were more specific and looked at the effects of writing on particular illnesses (e.g., asthma) and the associated symptoms (Hevey et al., 2012; Warner et al., 2006). 
Warner and colleagues (2006) and Smyth, Stone, Hurewitz, and Kaell (1999) examined the specific effects of written emotional disclosure on asthma. Smyth and colleagues also looked at the benefits of writing for arthritis patients. In both studies $(N=$ 162 combined), individuals with asthma or arthritis wrote for 15-20 minutes/day for 3 consecutive days. The objectives included looking at the effects of emotional disclosure on the health status of patients and presence of symptoms.

In both cases, health status improved and physical symptoms decreased following the intervention. Warner and colleagues (2006) measured asthma symptoms by using a 9-item self-report scale that asked about asthma and nasal/allergy symptoms. They reported that the disclosure group decreased physical symptoms from baseline to followup. Smyth and colleagues (1999) assessed asthma symptoms using spirometry, and arthritis symptoms were evaluated by a rheumatologist. They reported the asthma writing disclosure group had statistically significant greater improvement on asthma symptoms when compared to the control group, $F(1,55)=15.11, p<.001$. The arthritis groups had the same effect finding that the experimental group had statistically significant greater reductions in disease activity compared to the control group, $F(1,46)$ $=11.48, p=.001$.

In another example using a similar procedure, the influence of expressive writing on quality of life for myocardial infarction patients was explored (Hevey et al., 2012). The health-related quality of life (HRQOL) questionnaire was used to measure quality of life for both the treatment and control groups $(N=89)$. From baseline to 3-month followup patients in the expressive writing group reported statistically significant higher quality 
of life reports than those in the control group, $t(87)=2.04, p<.05$, Cohen's $d=.42$. Analyses were completed to examine any moderating effects of distress, personality, or coping. Specifically, Type D personality participants were of interest to the researchers because Type $\mathrm{D}$ personality individuals are characterized by suppressing feelings and experiencing high levels of negative affect. Type D personality participants in the EW group reported statistically significant greater benefits than non-Type D participants, demonstrating a moderation effect.

\section{Cognitive Functioning}

Cognitive improvements associated with EW primarily focused on academic performance. Burns and Friedman (2012) found that emotional expression was beneficial for female university students' math performance. The authors also looked specifically at the EW benefits for participants who experienced stereotype threat. The stereotype condition was set up by telling participants that the test they were taking was an investigation of math abilities, including strengths and weaknesses. The emotional expression group received instructions to express their emotions and the control group received no special instructions. The no stereotype condition participants were told that the math problems were being tested for future research. The 78 female students who participated were divided into a 2x2 design (emotional expression vs. control and stereotype threat vs. no stereotype threat). Both the stereotype threat and no stereotype threat groups who completed emotional expression performed better on the math equation statements than the control participants, $F(1,73)=3.68, p<.06, \eta^{2}=.05$. Participants in the stereotype threat group who completed emotional expression had 
higher self-perception of achievement than those in the control group, $F(1,74)=4.34, p$ $<.05, \eta^{2}=.06$

EW has also been associated with higher graduate entrance exam scores. Students $(N=104)$ preparing for graduate entrance exams (GRE, LSAT, MCAT, PCAT) were divided into two groups (experimental-EW and control). Students in the EW group were instructed to write about their deepest feelings about the upcoming exam. The authors used an analysis of covariance and described that all of the EW groups reported a decrease in depressive symptoms and EW participants scored higher on the entrance exam. The type of test was a moderating variable with students who took the LSAT or MCAT demonstrating more significant benefits of EW for exam performance (Frattaroli, Thomas, \& Lyubomirsky, 2011). A repeated study and a larger sample would be needed to examine mediating and moderating effects of personality, study habits, and anxiety in relation with EW and exam scores.

\section{Emotional Health}

A variety of emotional constructs, such as mood, self-esteem, and well-being, have been examined in expressive writing intervention research. Burton and King (2004) looked at the physical health benefits of writing about positive experiences for undergraduate students $(N=90)$ and the connection between writing and positive/negative mood. Mood is reflected in the positive or negative feelings (e.g., happy, pleased, confident, worried, upset, anxious). The experimental group wrote about an intensely positive experience and the control group wrote about a neutral topic. Mood was measured before and after participating in the writing exercise. Participants who 
wrote about intensely positive experiences reported enhanced positive moods after the intervention.

Looking specifically at body image and its impact on self-esteem, O'Connor and colleagues (2011) delivered an intervention to 158 women ages 18-22. The experimental groups wrote about body image success stories (WSS). The WSS group read stories about different women with successful image and the women's process. The participants then wrote in response to their reading about these successful image stories. The Written emotional disclosure (WED) group were asked to write about emotions and thoughts about a stressful experience related to their body. A control group wrote about nonemotional experiences. The study concluded that WED has more positive effect for selfesteem in relation to body image than WSS. This supports the effectiveness of expressive writing interventions for strengthening self-esteem among women.

Overall well-being has been addressed as one of many areas that can be positively influenced by expressive writing. Well-being includes psychological wellbeing (depression, anxiety), social wellbeing, life satisfaction, and stress. One study found that writing reflection assignments on satisfying life experiences were associated with greater levels of well-being (Bhullar et al., 2011).

\section{Social Relationships}

Social interactions impact our emotional and physical health (Fincham \& Beach, 2010). Lepore and Greenberg (2002) studied the physical effects of having a dating relationship end within the last year. Using a two-group, repeated measures design the participants either participated in an EW exercise or a neutral writing exercise 
approximately 7 months after the break up. Of the 145 undergraduate participants, those who were in the EW group (who wrote about the relationship, what it was like while in the relationship, etc.) did not report an increase in upper respiratory and other physical symptoms whereas the control group did report an increase. Authors give a variety of possible attributions of this finding. One is based on writing as a form of therapy that encourages individuals to process difficult situations. Similarly, it could be that processing through writing brings enhanced individual control over responses to stress.

Married couples in difficult circumstances, such as high conflict or military deployment, have also benefited from writing interventions (Baddeley \& Pennebaker, 2011; Jordan, 1998). Post deployment military couples $(N=102)$ participated in an EW intervention to explore the effects of EW on marital adjustment following deployment. For the majority of couples, the husbands were soldiers $(n=96)$. Six of the couples consisted of both husband and wife soldiers. Participants were divided into four groups: (1) soldier expressive and spouse expressive, (2) soldier expressive and spouse control, (3) soldier control and spouse expressive, and (4) solider control and spouse control. The participants completed three 15 minutes writing sessions in one day. Analyses using multiple repeated-measures ANOVAs indicate that marital satisfaction increased for post deployment couples in the EW group, especially when the soldier is involved with the EW exercises $(F=3.88)$ and if the soldier's combat exposure was above the median $(t=$ 2.45; Baddeley \& Pennebaker, 2011). 


\section{Writing Analysis Programs}

With an increase awareness of the possible benefits of writing, researchers have begun to examine where and why expressive writing exercises have the effects they do. Writing analysis programs have been developed to explore why these EW exercises are beneficial. Analyses examining expressive writing samples show correlations between health (physical and mental) and the words used (Pennebaker et al., 2007).

Through the use of text analyses, researchers have found certain writing characteristics are associated with greater benefit for participants in a variety of studies (Pennebaker et al., 2007). Characteristics such as amounts of positive and negative emotion words (Pennebaker et al., 1997), flexibility in pronouns (Campbell \& Pennebaker, 2003), and cognitive and emotional processing (Warner et al., 2006) are indicators that the author of the expressive writing will experience greater benefit compared to other participants. Different programs and protocols have been established to study the relationships of individual variables (e.g., health or mental variables) and components of written speech.

Although there are many writing analysis programs, only the programs most frequently used in the social sciences will be reviewed. These programs were chosen because they all emphasize analyzing components of writing samples. The Latent Semantic Analysis and Language Style Matching programs will briefly be covered with their purposes, uses, strengths, and weaknesses. A more in-depth review of the Linguistic Inquiry and Word Count will also be provided with similar details about the program and how it could be used to advance the field of research in this area. 


\section{The Latent Semantic Analysis}

Researchers developed the Latent Semantic Analysis (LSA) with the original purpose to assist with automatic indexing and retrieval by detecting similarities in writing (Deerwester, Dumais, Landauer, Furnas, \& Harshman, 1990). Problems with retrieval had been that programs could only decipher difference and similarities based on the words used and not differences and similarities on concepts expressed. The LSA also assesses and compares the semantic relationship and similarities between two pieces of written work (Foltz, Kintsch, \& Landauer, 1998). Coherence between two texts is calculated through a mathematical analysis. The direct and indirect relationships between words are calculated into a score that reflects the degree of related information between texts. The LSA does not account for the word ordering, omissions, substitutions, and references. Clauses that link ideas, such as therefore, are not included in the semantic analysis. Originality cannot be detected. Although the LSA provides strength in prediction, it does not account for syntactic features (Foltz et al., 1998). The LSA provides a useful tool to compare two or more units of text but does not provide a way to analyze what individual processes are reflected in writing samples.

Using the Latent Semantic Analysis (LSA), Campbell and Pennebaker (2003) explored relationships between writing content/style and the change in frequency of physician visits. Writing samples compiled from previous studies $(N=183)$ were used to analyze this relationship. Campbell and Pennebaker (2003) found there was a greater association with better health for those individuals whose writing changed over the course of the intervention. Delving deeper, changing pronouns (e.g., using more "me" 
and "us" overtime instead of "you" and "them") specifically predicted better health. The change in pronouns from day-to-day reflects flexibility and alterations in perspectives about self and social circumstances. No LSA research has included married couple writing samples.

\section{Language Style Matching}

The Language Style Matching (LSM) measure uses algorithms to calculate mimicry, or similarities, in language samples. Mimicry in verbal language gives insight into social dynamics. The LSM measures the amount of function words (e.g., propositions, conjunctions, articles) and compares the rates of function words between two or more writing samples. To start, a score is calculated for the use of function word categories for each participant. These scores are then compared with other participant scores that produce a dyadic or group LSM score. For example, personal pronouns are function words. Participant 1 has a $6.4 \%$ use of personal pronouns in a writing sample, and participant 2 the percentage use is $5.7 \%$. A final score is calculated in a range from 0 to 1 , with a score of 1 reflecting a $100 \%$ match of function-words between participants. The LSM does not analyze written documents line by line but as an entire interaction (Gonzales, Hancock, \& Pennebaker, 2010). Therefore, the LSM does not provide detailed analysis of the writing samples text. Conclusions from research using the LSM must be drawn from the text as a whole and not look at distinct functions of word choice and use. To understand emotional processing, a more detailed analysis of writing needs to be used. 
Similarities between partners are often a key component of romantic relationships (Ireland et al., 2011). Similarities in writing were analyzed by Ireland and colleagues (2011), using language style matching (LSM). Dating relationship stability was positively predicted by analyzing the writing samples of these couples. College-age dating couples with LSM scores above the median were more likely to still be together at the 3-month follow-up than the couples who had LSM scores at or below the median (odds ratio $=1.95)$. To date there is no LSM analyses including non-college married samples.

\section{The Linguistic Inquiry and Word Count}

The Linguistic Inquiry and Word Count (LIWC) is a word analysis program designed to advance research analysis of written responses. Pennebaker and colleagues (2007) developed the LIWC to provide an effective way to study emotional, cognitive, and structural mechanisms of speech. LIWC's internal dictionary facilitates writing samples analysis by categorizing words into different groups and counting the percentage of words in each category according to the total number of words in the writing sample. As opposed to previous writing analyses done without computer programs, the LIWC can analyze a large number of writing samples without compromising coding consistency. This program quantifies emotional content found in writing samples and has many beneficial applications (see Pennebaker et al., 2007; Tov, Ng, Lin, \& Qiu, 2013).

The LIWC provides a high-speed, effective analysis. A typed, single-spaced page of text can be processed in a fraction of a second (Pennebaker et al., 2007). In comparison with other widely-used word analysis programs, the LIWC offers the ability 
to analyze and dissect individual writing samples. The LSA and LSM are effective programs for comparing multiple writing samples but not for evaluating individual writing samples. With the LIWC's large dictionary, numerous categories, and the ability to create new categories, it is the only program that provides an in-depth look at the smallest components of written speech. The LIWC was developed based on thousands of writing samples. Updates and improvements have been made over time (see Pennebaker et al., 2007; Pennebaker, Francis, \& Booth, 2001). The main weakness of the LIWC is that it does not evaluate the context of which words are used. For example, the word "think" is evaluated the same in the following sentences: "I don't think about what happened" and "I think about what happened." Clearly, the sentences have vastly different meanings. Researchers have found ways to avoid this weakness by including phrases in the analysis (e.g., in the phrase "don't think," think would not be counted as an insight word; see Lee \& Cohn, 2010).

The rest of this section will illustrate important areas of research that includes the LIWC. Validation of the LIWC as a tool for quantifying emotional written content will be briefly discussed. An overview of studies examining the LIWC's association with self-report measures will be addressed.

In an innovative approach, the expressive writing model was used to examine social effects of writing in romantic relationships (Slatcher \& Pennebaker, 2006). This study was a combination of an expressive writing intervention and analysis. In the intervention portion of the study that included 86 undergraduate couples who were dating, each participant was either given the assignment to write about the emotional 
aspects of their relationship (thoughts and feelings) or about daily activities. Participants who wrote expressively about his or her relationship were more likely to be with the same partner 3 months later (Cohen's $d=0.54$ ).

The researchers also used the LIWC to analyze the couples' instant messaging from the days preceding and following the writing exercise. If participants had written about their relationships, more positive and negative emotion words were used in instant messaging following the writing exercise $(d=1.19)$. This means that participating the expressive writing condition changed the way that partners communicated. The increase in positive emotion words created a partially mediated effect for expressive writing and stability in the relationship (Slatcher \& Pennebaker, 2006).

The LIWC has been used to look at coping styles and coping processes. Coping styles illustrate individual responses to stressful experiences. The main broad coping styles are problem-focused, emotion-focused, and avoidance (Lee \& Cohn, 2010). Lee and Cohn (2010) reported that the LIWC can provide insight into the coping style of the writer. Use of negative words was related to depression scores and tended to have lower problem-focused strategies. Insight words was related to lower emotion-focus strategies.

Kahn, Tobin, Massey, and Anderson (2007) used the LIWC as a measure of emotional expression and examined the correspondence of the LIWC with self-report measures. The researchers assessed the construct validity of using the LIWC for this purpose in three different experiments. Amusement and sadness were used as the target emotions for the studies. 
In experiment 1, the authors "addressed whether the LIWC emotion counts are sensitive to differences in written essays about emotional autobiographical memories" (Kahn et al., 2007, p. 265). Students wrote three essays describing different experiences in their lives (an amusing experience, a sad experience, and a typical day). Hypotheses included that negative emotion word categories in the LIWC would be higher when writing about a sad experience and that positive emotion word categories in the LIWC would be higher for the writing samples about an amusing experience.

In the sad writing conditions LIWC showed that emotion word counts were lower in the total affect, positive emotion, and positive feelings categories when compared to the amusing writing conditions. Also, the sad writing conditions had higher word count means in the negative emotion and sadness/depression LIWC categories as compared to the amusing writing conditions. Experiment 1 supports that written samples about emotional experiences are written in a way that the LIWC can detect emotional expression (Kahn et al., 2007).

The shared purpose of experiments 2 and 3 was to expand the findings in experiment 1 and explore the validity of the LIWC in oral disclosures of current emotional experiences. Participants watched film clips that were designed to draw specific emotions (amusement or sadness). Hypotheses stated that following the "amusement" clip more words in the LIWC positive emotion and feelings categories would be used, and following the "sad" clip more words in the negative emotion and sadness/depression would be used. These hypotheses were supported in experiment 2 
(positive affect $F=52.21$, negative affect $F=18.98$ ) and experiment 3 (positive affect $F$ $=53.21$, negative affect $F=27.97$ ).

Experiment 3 additionally examined individual differences by including variable intensities of emotional experiences and personality measures. There was little evidence that individual differences in emotional expressivity and reactivity or personality difference are related to LIWC scores. Support was shown for a positive association between the impulse strength subscale of the Berkeley Expressivity Questionnaire and positive feelings category in the LIWC. After watching the comedy clip, the intensity of the momentary experiencing amusement scale had a positive relationship with positive categories in the LIWC, but this relationship was not found with the funeral clip and negative emotions (Kahn et al., 2007).

The daily diary entries of 206 participants were analyzed to determine how well an emotional experience was portrayed in the LIWC emotion coding (Tov et al., 2013). Participants completed a short survey every night for 3 weeks that included a self-report rating scale of experiences and a written report of two events of the day. Daily positive and negative emotional experiences were reported (happy, cheerful, sad, stressed) by rating the experiences from 0 (not at all) to 6 (extremely). A correlation between combined scores of positive, sadness, anger, and anxiety were calculated with the LIWC categories. These concurrent emotion scores had high reliability with the LIWC categories, ranging from .91-.94.

These studies show promise for the LIWC to be used as a tool for interventions and research. Often, self-reported measures are used as the main source of evaluating 
emotional and social processes. The LIWC presents itself as a method for measuring and evaluating social and emotional constructs and shows potential for being a companion to self-report measures. The relationship between the LIWC and self-reported measures is an area that is new to the research field and shows potential for future research. The vast majority of LIWC research only includes college students and the LIWC has not been used in studies that include married participants.

\section{Marital Satisfaction}

Marital relationships are one of the most studied topics in the field of marriage and family (Bradbury \& Karney, 2004; Fincham \& Beach, 2010; Vaillant \& Vaillant, 1993). Research indicates that marital satisfaction is associated with life satisfaction, depressive symptoms, and overall well-being (Fincham \& Beach, 2010). Marital relationships are important to study because of the grand effects and influences they have on many parts of society, including children outcomes and societal trends (Fincham \& Beach, 2010; Osborne \& McLanahan, 2007). Marital relationships differ from dating relationships in many ways, including commitment and stability (Osborne \& McLanahan, 2007). Including married couples could potentially be useful in the writing analysis field that has predominately only included college-age dating couples. A brief overview of some of the factors that influence marital satisfaction, will first be presented. A review of some aspects of marital satisfaction that potentially are linked with writing, including use of pronouns and positive and negative affect, will be given. 


\section{Factors Influencing Marital Satisfaction}

The study of marital satisfaction (MS) could include an almost infinite amount of factors. The complexity of MS includes climate, stressors, partner and outside support as well as individual and family histories (Fincham \& Beach, 2010). MS is based in emotional constructs, such as the positive and negative exchanges of couples. Communication and attitude play a role in couple satisfaction (Bradbury \& Karney, 2004). Many research studies show links between lower MS reports and depression, psychiatric disorders, health problems, use of substances, and anxiety (for a review, see Fincham \& Beach, 2010).

There are many other factors that influence MS. Communication, stress, length of marriage, gender, and emotional health all impact couples and relationship satisfaction. A brief review of some possible confounding variables that were included in this study will be given. The focus of the remainder of this section will be exploring the aspects of marital satisfaction that could possibly be linked to writing analysis outcomes.

\section{Individual Characteristics}

Individual characteristics, such as sex, also influence MS. Researchers have found that women tend to have a stronger link between social support and marital satisfaction, highlighting the difference in meaning of support for men and women (Acitelli \& Antonucci, 1994). Sex also has been linked to marital satisfaction due to differences in dealing with work stress. In dealing with negative work days, women were more likely to have angrier marital behavior and men were more likely to have increased 
withdrawn behaviors (Schulz, Cowan, Pape Cowan, \& Brennan, 2004). For example, stress and stress spillover can have a negative influence on MS. Yet, the support of a partner can buffer the effects of stress on the marital relationship (Brock \& Lawrence, 2008). In stressful settings and problem-solving, the way each partner copes affects changes in marital satisfaction (Bradbury \& Karney, 2004).

\section{Length of Marriage}

Length of marriage also influences MS. Demographic research has found that divorce rates are high in the first few years of marriage but much lower (between $1 \%$ and $2 \%$ ) in marriages of over 30 years (Raley \& Bumpass, 2003). This infers that the length of marriage may act as a stabilizer for the marriage (Mirecki, Chou, Elliott, \& Schneider, 2013). Another body of research indicates that marital satisfaction drops rapidly over the first 10 years of marriage and then continues to drop gradually (Glenn, 1998; Vaillant \& Vaillant, 1993). Both support the assumption that length of marriage is related to MS.

\section{Other Potential Confounding Variables}

All of the potential factors that influence MS cannot be measured in one study. For the purposes of this study, factors that were most likely to be related to MS and writing were included in the questionnaire. This allowed for the researchers to control for these variables in the analyses.

Religiosity and religious preference were included in this study because of ties made in previous research regarding MS and religious views. Curtis and Ellison (2002) found that couples who differ about theological ideas argue more than couples who have 
similar theological ideas. They also found that religious preference is associated with different conflicts within a relationship. Religious preference was also included because some religious denominations explicitly encourage frequent journal writing. The frequency of journal writing was controlled for in this study.

\section{Power of Pronouns}

The use of personal pronouns has been significant in analyzing the effects of writing (Campbell \& Pennebaker, 2003). Based on the work of Sillars, Shellen, McIntosh, and Pomegranate (1997), the conversations of married couples who report higher marital satisfaction will differ in the uses of pronouns. The specific use of first personal plural pronouns (e.g., we, us) has reflected marital satisfaction in interviews of traditional married couples (Sillars et al., 1997). This is indicative of participants giving their spouse "cognitive room" (Gottman \& Silver, 1999). In other words, personal pronouns (singular or plural) may indicate where an individual perceives his/her relationship on the continuum of individuality and togetherness.

Subtle differences in language can communicate different perceptions about relationships. Mutuality, for example, is found in relationships with a high amount of overlap in their lives as a couple. This means they see themselves as a couple more than separate individuals. The use of pronouns demonstrates mutuality and influences the way a relationship is perceived (Miller, 2012). The use of more words in the first personal plural pronouns category was hypothesized to be reflective of higher marital satisfaction.

Language influences relationships and the interactions within relationships. In a study of 189 undergraduates, the perception differences based on pronoun use was 
examined. All participants received a paragraph describing a friendship between the author of the paragraph and Valerie. Ninety-one participants read a description that used first personal plural pronouns (e.g., we) and 98 participants read a description that used first personal singular pronouns (e.g., Valerie and I). After reading the friendship description participants were asked to complete a questionnaire about the relationship and describe the friendship using the Inclusion of Others in Self Scale. The results were as hypothesized; the we group reported that the friendship was closer $(M=3.23)$ and higher in quality $(M=6.07)$ than the Valerie and I group $(M=2.94, M=5.54$, respectively). This study supports that language that is often considered incidental and unimportant may be related to perceptions of relationships (Fitzsimons \& Kay, 2004).

Agnew and colleagues (1998) theorize that self-perceptions change as relationship commitment increases. These changes include seeing oneself more as a part of a collective entity (self and partner collectively) than as an individual. The authors postulate that an individual's perception of self and collectively with partner would be made manifest through first personal plural and possessive pronouns. The premise of the authors was that participants who were more committed in their relationships would exhibit more plural pronouns. Students in introductory psychology classes $(N=200)$ were asked to complete a questionnaire and write about a current close relationship. A measure of partner closeness, centrality of the relationship in the individual's life, and commitment were assessed in addition to the writing exercise. A composite of the number of plural pronouns, partner closeness, and centrality of relationship was computed for a total cognitive interdependence score. Commitment was correlated with 
the total computed score $(r=.66, p<.01)$. Notably for the purpose of the current study, commitment was also correlated with the number of plural thoughts $(r=.16, p<.05)$. This supports the proposition that there is an association between plural pronoun use and commitment to a romantic relationship (Agnew et al., 1998).

\section{Positive/Negative Affect}

Positive and negative expressions are important factors in looking into the emotional processes of individuals. Positive expression in writing is related to positive mood about life situations (Burton \& King, 2004). Positive affect has also moderated the effects of problem-solving skills that influence marital quality (Bradbury \& Karney, 2004; Fincham \& Beach, 2010) and low positive affect is related to declines in marital satisfaction (Fincham \& Beach, 2010). Positive expression has been seen to increase when individuals write about their relationship. Positive expression also partially mediates the relationship between writing and couple stability (Slatcher \& Pennebaker, 2006). The positive expression category was examined to see if couples who reported high marital satisfaction used more positive emotion words than those with lower marital satisfaction.

The relationship between premarital affect and postnuptial relationship satisfaction has been examined. Engaged couples $(N=43$ couples $)$ participated in two 10-minute problem-solving discussions with one topic chosen by the wife and one topic chosen by the husband. These discussions were then coded for positive (humor, affection, or interest) or negative (anger, contempt, sadness, or anxiety) affect. Coders attained acceptable reliability for men's and women's affective behaviors, ranging from 
.84-.94. Positive affect displays during coded discussions and relationship satisfactions were positively correlated. The men's statistically significant correlations ranged from $.41-.53$, with $p$ values less than the $<.05$ level. The women's significant correlations ranged from .35-.55, also with $p$ values at least at the $<.05$ level. This supports that the affective climate of a marriage plays a role in the satisfaction of the couple (Mattson et al., 2011).

In another study, 172 newlywed couples participated in a longitudinal study examining the influence of skills and affective expressions on marital satisfaction trajectories. Similar to Mattson et al. (2011), couples participated in two discussions which were then coded. The results concluded that affect codes are a reliable predictor of marital satisfaction. The data show the correlations range from -.28 to .28 . The study indicates that high quantities of negative skills and low quantities of positive affect predict rapid rates in marital satisfaction decline. Results also indicate that high levels of positive affect buffer the effects of high amounts of negative skills (Johnson et al., 2005).

The affective climate for conflict, for example, is influenced by the amount of positive and negative affect. The affective climate of conflict has been seen as a contributor to marital satisfaction changes over time (Fincham \& Beach, 2010). Declines in marital satisfaction are quicker when there are high levels of negative affect and low levels of positive affect. On the other hand, high levels of positive affect may act as a buffer to the effects of high levels of positive affect (Fincham \& Beach, 2010). When positive interactions with partners were considered, couple conflict did not predict marital satisfaction. 


\section{Conclusion and Research Questions}

The purpose of this study was to explore the relationship between writing and marital satisfaction. Words reflect who individuals are, the relationships they are in (Tausczik \& Pennebaker, 2010), and also communicate perceptions about relationships (Fitzsimons \& Kay, 2004). Language and writing analysis programs provide an effective way to quantify emotional, cognitive, and structural components of written speech. Like verbal expression, written expression provides insights into the cognitive and emotional world of an individual. To date, most of writing research has looked at intrapersonal benefits. More research is needed to look at the relationship between writing and interpersonal benefits. Using writing analysis techniques to study marital relationship offers potential benefits for couple interventions and future research examining marital satisfaction.

The concept of examining the relationship between writing analyses and standardized measures has been explored (Tov et al., 2013) but has not included the context of marriage and marital satisfaction. The majority of expressive writing research, has included college-age participants (Burns \& Friedman, 2012; Burton \& King, 2004; Frattaroli et al., 2011; Lee \& Cohn, 2010; O'Connor et al., 2011; Slatcher \& Pennebaker, 2006) and all research that includes relationships and writing analysis has only included dating couples (Lepore \& Greenberg, 2002; Slatcher \& Pennebaker, 2006). It was not clear how writing analysis research findings will translate to married couples at different stages of life. Based on existing literature and symbolic interactionism framework, the 
goal of this study was to enhance understanding of the relationship between writing samples and marital satisfaction.

There were two specific research questions for this study:

(1) What is the relationship between personal pronouns (specifically first person plural and first person singular pronouns) and marital satisfaction?

This question included examining what actor and partner effects exist in terms of personal pronouns and marital satisfaction. Question 1 also included exploring possible sex and length of marriage differences between personal pronouns and marital satisfaction.

(2) What is the relationship between affective language and marital satisfaction? This question included examining what actor and partner effects exist in terms of affect and marital satisfaction. Question 2 also included exploring possible sex and length of marriage differences between affect and marital satisfaction. 


\section{CHAPTER III}

\section{METHODS}

The purpose of this study was to examine the overall strength of association between expressive writing and marital satisfaction. Data was gathered from married couples who participated in a writing exercise about their relationship. Relationships between writing and marital satisfaction were then analyzed. This chapter will discuss the research design, subjects, procedures, measurement, and data analyses that were used for the purpose of this study.

\section{Research Design}

For the purposes of this study, a correlational design was used to examine the relationship between marital satisfaction and expressive writing. The purpose of the correlational design was to explore relationships between the dependent variables and the independent variables (Gall, Gall, \& Borg, 2006). For this study, marital satisfaction was the dependent variable and expressive writing (specifically the variables of pronoun usage and affective language) was the independent variable. The correlational design provided insight into the strength of the relationships between the writing and marital satisfaction.

\section{Sample}

Because this was an exploratory study, a nonprobability sampling method was used. Sample criteria included that participants must be married and 18 years of age or 
older. Both members of the couple were asked to participate. Different aspects of marital relationships and satisfaction come to light when both spouses participate (Acitelli \& Antonucci, 1994; Bradbury \& Karney, 2004; Brock \& Lawrence, 2008; Schulz et al., 2004). Married couples were also chosen for the purpose of this study because they tend to be stable and committed (Osborne \& McLanahan, 2007). This is also important because most of the writing research has included college-age, dating couples (Lepore \& Greenberg, 2002; Slatcher \& Pennebaker, 2006) and married couples haven't been included in writing analysis research.

Using a $\mathrm{G}^{*}$ Power analysis, for power $=.95$ to detect an effect size of $r=.5$ and alpha of 0.05 , the minimum enrollment needed to be 42 couples (Faul, Erdfelder, Buchner, \& Lang, 2009). For the purpose of understanding nuances in the data the targeted enrollment for this study was 60 couples. There were a total of 173 participants in this study, 91 females and 82 males. The sample included 79 couples where both spouses completed the study. Seventeen spouses did not participate in the study (13 men and 4 women). See Table 1 for the demographic characteristics of the sample. Length of marriage ranged from less than a year to 48 years $(M=16.09, S D=12.95)$. Number of children ranged from zero to eight $(M=2.54, S D=2.14)$. The majority of the

Table 1

Summary of Demographic Characteristics of the Sample

\begin{tabular}{lcrrr}
\hline & \multicolumn{2}{c}{ Husbands } & \multicolumn{2}{c}{ Wives } \\
\cline { 2 - 5 } & $M$ & $S D$ & & \multicolumn{1}{c}{$S D$} \\
\hline Age (years) & 41.02 & 14.38 & 37.67 & 13.83 \\
Education level & 16.00 & 2.71 & 14.66 & 2.03 \\
(years) & & & & \\
\hline
\end{tabular}


participants were Caucasian (97\%) and reported LDS as their religious preference (88.4\%). See Table 2 for categorical characteristics of the sample.

\section{Procedures}

\section{Recruitment}

The researcher visited general education courses at Utah State University to ask students to recruit married couples to participate in this study. General education courses were used because of the cross-section of majors and using the snowball effect, students could participate themselves or recruit their parents, other relatives, or unrelated associates to participate in the project. As hoped, participating couples varied in age and length of marriage. Materials and/or access to online study materials was given to students who then either participated in the project themselves or delivered materials and information to a recruited couple who was interested in participating. All students who recruited at least one couple to participate in the study had their names placed in a drawing to receive a $\$ 50$ gift card. Although the researcher was prepared to offer extra encouragement to recruit couples who had been married for specific lengths of time (e.g., couples married over 30 years, newlyweds, etc.), there was sufficient variety in the sample and no extra encouragement was needed.

All packet materials were available online, via Qualtrics, or in a hard copy form. Participants were instructed to choose which method of writing was most natural for them. All of the participants chose to complete the study online. Both online and hard copy packets included the same items. A letter of information was included in the packet 
Table 2

Summary of Categorical Characteristics of the Sample

\begin{tabular}{|c|c|c|}
\hline & Husbands (\%) & Wives (\%) \\
\hline \multicolumn{3}{|l|}{ Household income } \\
\hline Under $\$ 19,999$ & 14.6 & 15.6 \\
\hline$\$ 20,000$ to $\$ 39,999$ & 12.5 & 16.7 \\
\hline$\$ 40,000$ to $\$ 59,999$ & 13.5 & 16.7 \\
\hline$\$ 60,000$ to $\$ 79,999$ & 8.3 & 7.3 \\
\hline$\$ 80,000$ to $\$ 99,999$ & 11.5 & 13.5 \\
\hline Over $\$ 100,000$ & 25.0 & 24.0 \\
\hline \multicolumn{3}{|l|}{$\begin{array}{l}\text { Outlook on life is based on } \\
\text { spiritual beliefs }\end{array}$} \\
\hline Strongly disagree & 1.0 & 1.0 \\
\hline Disagree & 0.0 & 2.1 \\
\hline Neither agree nor disagree & 7.3 & 6.3 \\
\hline Agree & 19.8 & 16.7 \\
\hline Strongly agree & 58.3 & 67.7 \\
\hline \multicolumn{3}{|l|}{ Frequency of journal writing } \\
\hline Never & 33.3 & 28.1 \\
\hline Yearly & 24.0 & 24.0 \\
\hline Monthly & 13.5 & 24.0 \\
\hline Weekly & 7.3 & 12.5 \\
\hline Daily & 8.3 & 6.3 \\
\hline \multicolumn{3}{|l|}{ Date frequency } \\
\hline Never & 1.0 & 0.0 \\
\hline Weekly & 49.0 & 45.8 \\
\hline Monthly & 35.4 & 46.9 \\
\hline Yearly & 1.0 & 3.1 \\
\hline \multicolumn{3}{|l|}{$\begin{array}{l}\text { Frequency of daily } \\
\text { communication }\end{array}$} \\
\hline $0-3$ times & 6.3 & 7.3 \\
\hline 4-7 times & 21.9 & 24.0 \\
\hline 8-10 times & 15.6 & 19.8 \\
\hline 11-14 times & 8.3 & 15.6 \\
\hline $15+$ times & 34.4 & 29.2 \\
\hline \multicolumn{3}{|l|}{ Marital satisfaction } \\
\hline Nondistressed & 95.8 & 92.7 \\
\hline Distressed & 4.2 & 7.3 \\
\hline
\end{tabular}


given to participants (see Appendix A). The letter of information explained that upon completing the materials packet, participants gave their informed consent. The letter of information was written in language that will be easy to understand by readers of this age group.

The confidentiality of each participant was protected by instructing the participants NOT to put their names on their materials. Because all participants chose to complete the study online, none of the prepared procedures for completing and returning hard copies were needed. Potential hard copy participants would have been instructed to put completed materials in a pre-stamped, self-addressed envelope. Individuals who completed hard copy materials would have been given an ID number to classify them individually and as a couple. All hard copy research materials would have been kept in a locked filing cabinet in the primary researcher's office. The primary researcher would have been the only person with access to the file. All online research materials were kept on an encrypted, secure website. The instructions packet informed participants that a list of mental health professionals was available through the principle investigator should the writing exercise cause any distress. This study was approved by the Institutional Review Board of Utah State University.

\section{Data Collection}

Student recruiters gave the materials packet or online information to potential participants. Materials included a letter of information, instructions, and two questionnaires (one for each spouse). Hardcopy and online materials included a code for each couple to enter into the survey for the purpose of being able to later link husband 
and wife together for data analysis. Hard copy packets also included paper for writing purposes, and two, pre-stamped, self-addressed sealable envelopes to return completed materials. Couples who participated online or with hard copy materials were instructed to read through the letter of information, fill out the questionnaire, and individually write in separate rooms or at separate times for 15-20 minutes about their marital relationship. The instructions for the writing exercise were adapted from Pennebaker's writing instructions (1997). The instructions were:

Write about something you feel strongly about in the relationship with your spouse. Really let go and explore your thoughts, feelings, and experiences. All of your writing will be completely confidential. Don't worry about spelling, sentence structure, or grammar. The only rule is once you begin writing, continue to do so until the15-20 minute time is completed.

The analysis program processes files with word text, not handwriting samples. Therefore, the participants with handwritten writing samples would have been transcribed by undergraduate student researchers who have IRB training. Because all participants completed the study online, the use of undergraduate students as transcribers was not needed and, therefore, no nonrandom bias was introduced to this study because of differences in transcribing proficiency. 


\section{Measurement}

\section{Demographics Survey}

For the purpose of describing the sample, a 13-item demographics survey was given. The items included sex, age, education level, income, ethnicity, length of marriage, number of times married, number of children, religiosity, religious preference, frequency of journal writing and questions about couple behaviors (frequency of going on dates and frequency of communication throughout the day; see Appendix B).

\section{Writing Analysis}

Participants' writing was analyzed using the Linguistic Inquiry and Word Count, 2007 (LIWC; Pennebaker et al., 2007). Pennebaker and colleagues developed the LIWC as a method to explore the emotional, cognitive, and structural components that exist in writing samples. The LIWC is a strong text analysis program with strong psychometric properties (Pennebaker et al., 2007). The LIWC2007 is a program that analyzes words and categorizes words into 80 domains or categories. Using an internal dictionary of 4,500 words and word stems, the LIWC2007 quickly and efficiently analyzes word files by reading each file one word at a time. Each word is matched with the dictionary word and given the appropriate category name. Structural composition elements, such as word count and sentence punctuation, are also incremented. The LIWC has demonstrated strong reliability and predictive validity (Pennebaker et al., 2007; Pennebaker \& King, 1999). 
A subset of the 80 LIWC categories was identified as the focus categories for this study (see Table 3). Based in prior research, these were the categories that most likely influence marital satisfaction. The focus group included personal pronouns (first person plural and first person singular) and affective processes (positive and negative affective language). The category of word count (total words in the writing sample) was also included in the analysis as a covariate to control for the effect of the length of writing.

\section{Marital Satisfaction}

Marital satisfaction was measured using the Couples Satisfaction Index (CSI; Funk \& Rogge, 2007). This measure was chosen because it is reliable, valid, and relatively short. For this study, the CSI-16 was used. Questions are answered using Likert scales that differ with each item but in general range from 0-5 (e.g., $5=$ always agree to $0=$ always disagree or $0=$ not at all true to $5=$ completely true). Sample questions included "In general, how often do you think that things between you and your partner are going well?" and "My relationship with my partner makes me happy." The

Table 3

LIWC Category Examples

\begin{tabular}{ll}
\hline Category & Examples \\
\hline Personal pronouns & I, them, her \\
$\quad$ First personal singular pronouns & I, me, mine \\
$\quad$ First personal plural pronouns & We, us, our \\
Positive emotion & Love, nice, sweet \\
Negative emotion & Hurt, ugly, nasty \\
Anxiety & Worried, fearful, nervous \\
Anger & Hate, kill, annoyed \\
Sadness & Crying, grief, sad \\
\hline
\end{tabular}


CSI was developed to address the lack of precision found in the widely used and validated relationship satisfaction measures. The development of the CSI included an item-response theory analysis of survey responses from a large sample $(N=5,315)$ with 180 items that included questions from eight self-report measures and 75 other items. Results of the analysis demonstrated that the most widely used relationship satisfaction measures have low levels of accuracy in drawing results about relationship satisfaction.

The application of item response theory and principal-components analysis was also used to create the CSI. Differences in levels of satisfaction are powerfully detected with the CSI. The CSI has strong construct validity and internal consistency. Also, the CSI uses the same theoretical constructs as previous scales as is demonstrated by strong convergent validity. CSI reliability for this study was $\alpha=.95$.

\section{Data Analytic Strategy and Approach}

For the purposes of understanding the results of this study, a dyadic approach was used to examine the relationship between marital satisfaction and expressive writing. It is important to explore the relationship between individual (actor) and intrapersonal (partner) effects of pronoun and affect use in writing and marital satisfaction (Kenny, Kashy, \& Cook, 2006).

All participants in this study were married. Data from individuals within romantic relationships were more likely to be similar than data from other individuals. Therefore, within a couple, each participant's individual scores were affected by similar sources, influences, experiences, and each other. For this purpose, a dyadic data analysis 
was used (Kenny et al., 2006). This method accounts for the dyadic connection between participants within a couple and discounts the assumption that data from each individual is not related to data of another individual in the study. Discounting the potential of mutual influence of partners would increase the likelihood of Type I or Type II errors, depending on the analysis. Dyadic analysis minimizes errors by treating partner data as non-independent and accounts for the potential influence partners have on each other's relationship. The dyadic nature of the analysis provides practical usefulness in understanding how to intervene in couple relationships (at the individual or couple level) and how individuals in a relationship influence one another (Kenny et al., 2006).

To answer the research questions, this study used a dyadic analysis model called the actor-partner interdependence model (APIM; Kenny et al., 2006; Figure 1). The APIM analysis allowed the examination of how much a person predicts his/her own outcome (actor effects) and examine how much that a partner contributes to the person's outcome (partner effects). Partner effects make it possible to analyze mutual influence between partners (Kenny et al., 2006). Because participants in this study were married and both husband and wife were asked to participate, this analysis provided greater insight into the results. Analyzing results based on participants being independent from one another wouldn't have allowed for mutual influence to be explored. APIM analyses can typically be done using structural equation modeling (SEM) or multilevel modeling (MLM). For the purposes of this study, we used MLM using SPSS. 


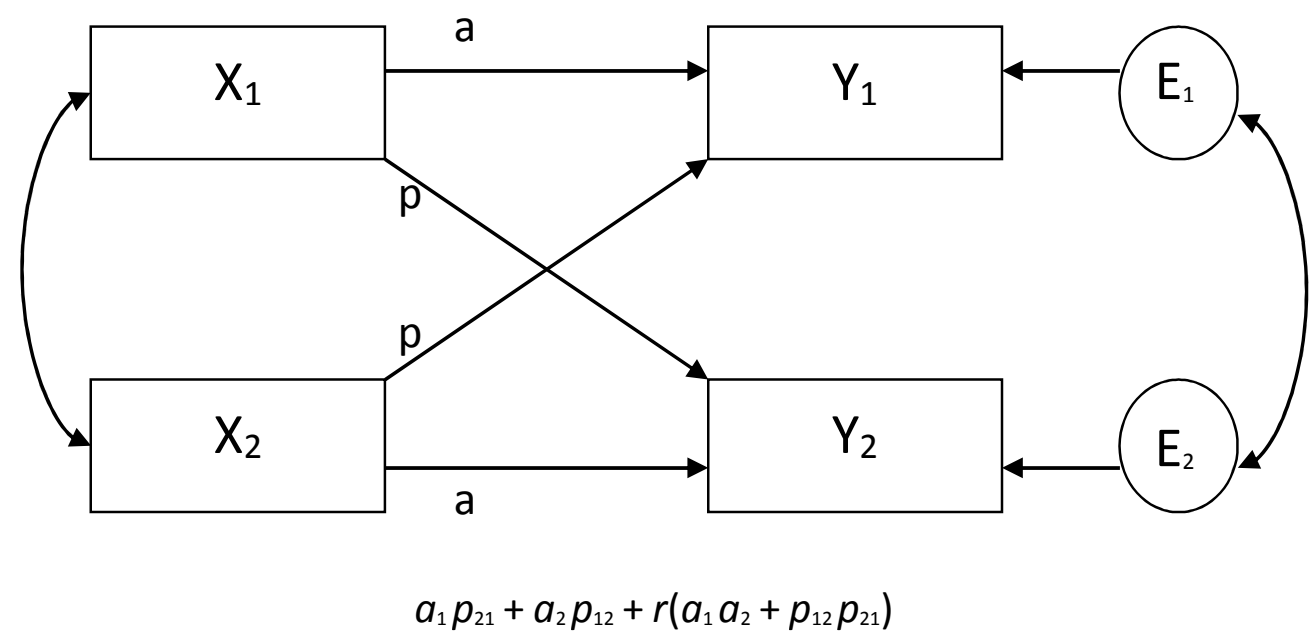

Figure 1. The actor-partner interdependence model (APIM; Kenny et al., 2006). 


\section{CHAPTER IV}

\section{RESULTS}

The purpose of this study was to increase the understanding of the relationship between marital satisfaction and writing. Specifically, the purpose was to examine the relationship between marital satisfaction and the way individuals write about their relationship (pronoun and affective language use). This study included data from husbands and wives who completed a demographics questionnaire, a marital satisfaction survey, and wrote about his/her marital relationship. The following chapter outlines the process of organizing and decisions of models and analyses results used to answer research questions.

Preliminary correlation analyses helped examine the relationship between variables (see Table 4). For men and women, marital satisfaction was positively correlated with frequency of daily communication between spouses and positive emotion language use. Marital satisfaction was also negatively correlated with length of marriage. There were a few sex differences found in the correlations. First person plural pronouns were significantly positively correlated with marital satisfaction for women but not for men. Negative emotion language was negatively correlated with marital satisfaction for women but not for men.

There was very little missing data in this study. None of the 13 demographic variables or 16 self-report items had more than $2 \%$ of responses missing. 


\section{Analysis Model Decision Process}

The following describes the decision-making process used in each analysis. Each analysis began with gender as a distinguishing variable and included demographic variables. Each analysis was guided by the retention or removal of variables to increase parsimony and power. Gender was kept as a distinguishing variable if there was a main effect involving gender or if a deviance test using chi-square and log-likelihood analyses (Kashy \& Donnellan, 2012) demonstrated that the additional complexity introduced by gender was justified. If neither of these criteria were met, then gender was removed and the data were treated as non-distinguishable. Distinguishing by gender was not justified in any of the final dyadic analyses for this study.

Demographic variables were included in the analyses because of their potential relationship with marital satisfaction. Demographic variables included in each original model were gender, length of marriage, number of children, education level, income, and ethnicity. All demographic variables began in the model but were removed if not significant. Covariates in each original model included frequency of journal writing (possible confound if participants write often), frequency of dates with spouse (possible confound depending on amount of time spent together), and daily communication with spouse (possible confound depending on how often couples communicate). These covariates began in each model but were removed if not significant. Total word count for actor and partner were also included in the model and were kept regardless of their significance because of potential confounds. Total word count was controlled for in each model so significance of variables is not based on a function of how much individuals 
Table 4

Bivariate Correlations for Demographic and Covariate Variables by Sex of Spouse

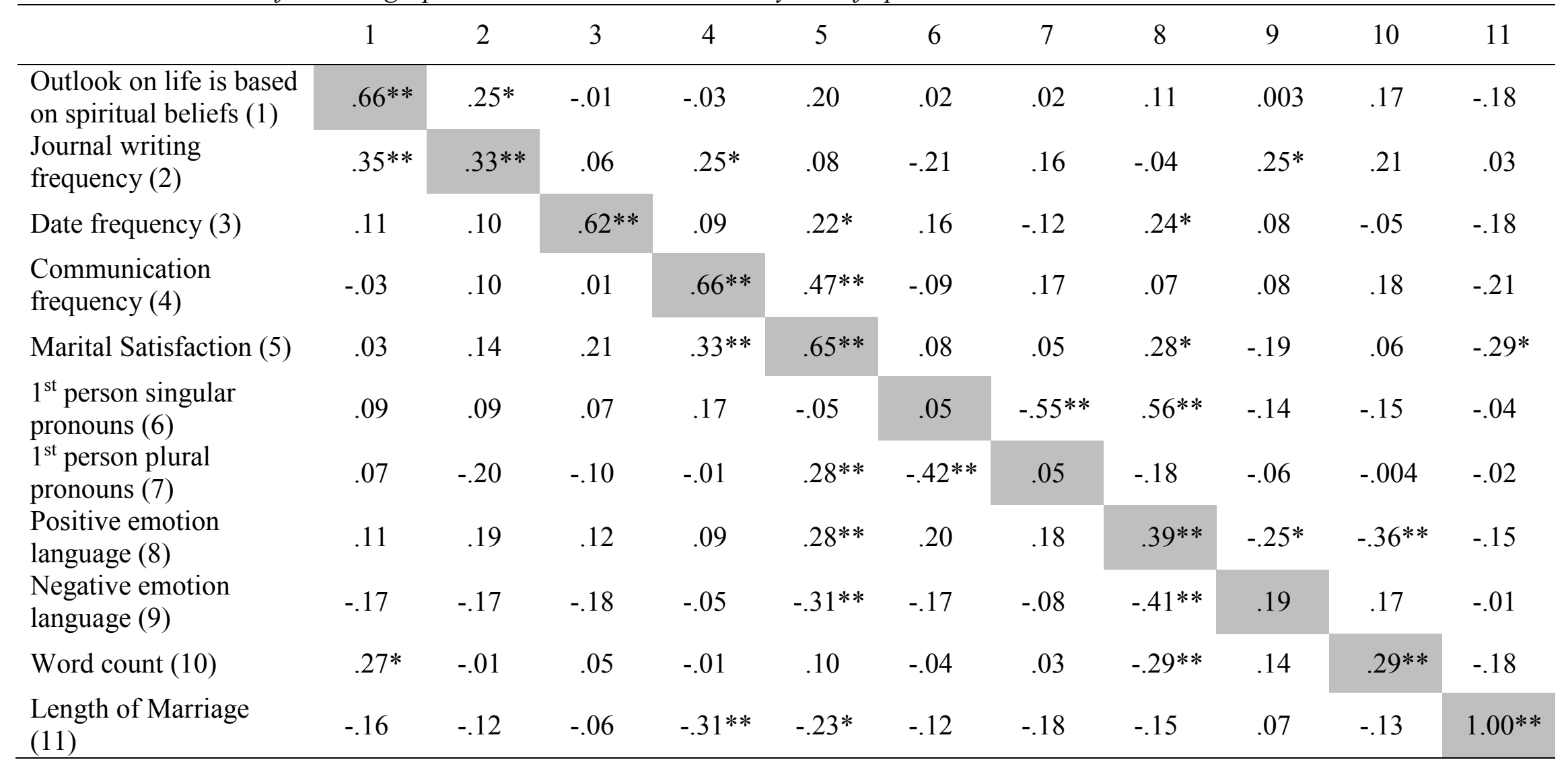

Upper-right cells - Correlations between variables for men

Lower-left cells - Correlations between variables for women

Trace-Correlations between men and women

$* p \leq .05 * * p \leq .01$ 
wrote. The variables included in each of the final models are described below in Tables 5-7 for each specific research question.

\section{Research Question 1: What Is the Relationship Between Personal Pronouns (Specifically First Person Plural and First Person Singular) and Marital Satisfaction?}

This question included examining what actor and partner effects exist in terms of personal pronoun use and marital satisfaction. Question 1 also includes exploring possible sex and length of marriage differences between personal pronouns and marital satisfaction.

The variables included in the final model for research question 1 are shown in Table 5. The amount of first person plural (e.g., "we" and "us") pronoun use of the actor was significant, $b=.58, t(130.35)=2.14, p \leq .05$. It is interesting to note that the amount of first person singular (e.g., "I" and "me") pronoun use by the actor did not have a significant negative or positive effect, $b=.24, t(121.93)=1.16, p=.25$. In other words, those who used more first person plural pronouns in their writing were likely to report greater satisfaction in their relationship demonstrating that there is a relationship between first person plural pronouns and marital satisfaction. However, there was no relationship between first person singular pronouns and marital satisfaction.

Although sex and length of marriage were included in the research questions, neither was significant and thus were not included in the final analyses for either question. Sex and length of marriage were considered variables that may influence 
Table 5

Model for First Person Pronouns and Marital Satisfaction

\begin{tabular}{|c|c|c|c|c|}
\hline & $b$ & SE & $d f$ & $t$ \\
\hline Date frequency & $3.33 * *$ & 1.26 & 136.23 & 2.65 \\
\hline Communication frequency & $2.88 * * *$ & .54 & 135.35 & 5.37 \\
\hline Word count (actor) & -.0003 & .004 & 128.34 & -.07 \\
\hline Word count (partner) & $.01 *$ & .003 & 123.03 & 2.34 \\
\hline $\begin{array}{l}\text { First person singular } \\
\text { pronouns (actor) }\end{array}$ & .24 & .21 & 121.93 & 1.16 \\
\hline $\begin{array}{l}\text { First person singular } \\
\text { pronouns (partner) }\end{array}$ & .31 & .20 & 111.24 & 1.56 \\
\hline $\begin{array}{l}\text { First person plural } \\
\text { pronouns (actor) }\end{array}$ & $.58^{*}$ & .27 & 130.35 & 2.12 \\
\hline $\begin{array}{l}\text { First person plural } \\
\text { pronouns (partner) }\end{array}$ & .30 & .25 & 122.15 & 1.19 \\
\hline
\end{tabular}

significant differences in writing samples and marital satisfaction. The results from this study indicate that there are no sex and length of marriage differences.

\section{Research Question 2: What Is the Relationship Between Affective Language Use and Marital Satisfaction?}

This question includes examining what actor and partner effects exist in terms of the types of affect words used in relationship-focused writing and their relationship with marital satisfaction. Question 2 also includes exploring possible sex and length of marriage differences between affect and marital satisfaction.

The final model for research question 2 is summarized in Table 6. Positive affective language of actors was significant, $b=.85, t(134.10)=3.44, p \leq .001$, indicating 
that those who used more positive language in their writing also reported greater marital satisfaction. This was also reflected in the partner's positive emotion, $b=.62, t(122.26)$ $=2.84, p \leq .01$. In other words, those whose partners used more positive language in their writing were likely to report greater marital satisfaction. Main effects for indicators of negative emotion for both actors, $b=-.95, t(119.38)=-1.75, p=.08$ and partners, $b=$ $-1.09, t(114.30)=-1.93, p=.06$ were not significant. These results support that there is a relationship between affective language use, specifically positive affective language use, and marital satisfaction. The results do not suggest that the amount of negative affective language use is related to marital satisfaction. This may indicate the importance of positive affect in association with relationship satisfaction.

Table 6

Model for Affective Language and Marital Satisfaction

\begin{tabular}{|c|c|c|c|c|}
\hline & $b$ & $\mathrm{SE}$ & $d f$ & $t$ \\
\hline Communication frequency & $3.03 * * *$ & .48 & 126.72 & 3.28 \\
\hline Word count (actor) & .01 & .003 & 122.06 & 1.85 \\
\hline Word count (partner) & $.01 * * *$ & .003 & 119.79 & 3.69 \\
\hline $\begin{array}{l}\text { Positive affective } \\
\text { language (actor) }\end{array}$ & $.85 * * *$ & .25 & 134.10 & 3.44 \\
\hline $\begin{array}{l}\text { Positive affective } \\
\text { language (partner) }\end{array}$ & $.62 * *$ & .23 & 122.26 & 2.84 \\
\hline $\begin{array}{l}\text { Negative affective } \\
\text { language (actor) }\end{array}$ & -.95 & .54 & 113.38 & -1.75 \\
\hline $\begin{array}{l}\text { Negative affective } \\
\text { language (partner) }\end{array}$ & -1.09 & .56 & 114.30 & -1.93 \\
\hline
\end{tabular}


A second model for analysis was included to further explore this research question. Because negative emotion language of partner approached significance, $b=$ $-.95, t(114.30)=-1.93, p=.06$, the question of an effect for specific types of negative emotion arose. This model was the same as the original model for this question with the exception that the actor and partner negative emotion language variables were replaced by actor and partner anxiety, anger, and sadness language variables. The variables included in the final model are included in Table 7. Positive emotion language of actors was still significant, $b=.85, t(133.93)=3.36, p \leq .001$, as was partner positive emotion, $b=.58, t(127.26)=2.61, p \leq .01$. With respect to actor and partner anxiety, anger, and sadness language, only actor anger language was significant, $b=-2.64, t(101.17)=-2.36$, $p \leq .05$, indicating that those who used more angry language in their writing also reported lower marital satisfaction. This model answers the research partner anxiety, anger, and sadness language, only actor anger language was significant, $b=-2.64, t(101.17)=-2.36$, $p \leq .05$, indicating that those who used more angry language in their writing also reported lower marital satisfaction. This model answers the research question by demonstrating that there is a relationship between affective language use (specifically positive affective language and anger language use) and marital satisfaction. However, expressions of anxiety and sadness in relationship-focused writing do not seem to have a relationship with marital satisfaction.

Taken all together, the use of pronouns and affective language in writing samples are associated with marital satisfaction. Specifically, those who use more first person plural pronouns in writing report higher marital satisfaction. Findings also included that 
Table 7

Follow-up Model for Affective Language and Marital Satisfaction

\begin{tabular}{|c|c|c|c|c|}
\hline & $b$ & $\mathrm{SE}$ & $d f$ & $t$ \\
\hline Communication frequency & $3.31 * * *$ & .50 & 127.78 & 6.56 \\
\hline Word count (actor) & .01 & .003 & 122.52 & 1.49 \\
\hline Word count (partner) & $.01 * * *$ & .003 & 121.26 & 3.26 \\
\hline $\begin{array}{l}\text { Positive affective } \\
\text { language (actor) }\end{array}$ & $.85^{* * *}$ & .25 & 133.93 & 3.36 \\
\hline $\begin{array}{l}\text { Positive affective } \\
\text { language (partner) }\end{array}$ & $.58 * *$ & .22 & 127.26 & 2.61 \\
\hline Anxiety language (actor) & 1.20 & 1.48 & 120.01 & .81 \\
\hline $\begin{array}{l}\text { Anxiety language } \\
\text { (partner) }\end{array}$ & .45 & 1.42 & 166.54 & .32 \\
\hline Anger language (actor) & $-2.64^{*}$ & 1.12 & 101.17 & -2.36 \\
\hline Anger language (partner) & -1.88 & 1.18 & 114.02 & -1.59 \\
\hline Sadness language (actor) & -1.76 & 1.72 & 111.54 & -1.02 \\
\hline $\begin{array}{l}\text { Sadness language } \\
\text { (partner) }\end{array}$ & -.68 & 1.66 & 94.05 & -.41 \\
\hline
\end{tabular}

participants who use more positive affective language in writing or whose partners use more positive affective language in writing reported higher marital satisfaction. Those who wrote with generally negative affective language did not report lower marital satisfaction, but writing with more anger words was associated with lower marital satisfaction. 


\section{CHAPTER V}

\section{DISCUSSION}

The purpose of this study was to gain better understanding of the relationship between writing and marital satisfaction. Writing provides a symbolic way to explore thoughts, emotions, and feelings through words (Lepore \& Smyth, 2002). Although research has found links between physical/mental health and the way people write (Pennebaker, 1997), there has been no research examining the intrapersonal effects, symbols, and insights of couple writing samples. Using the LIWC, writing samples from married couples were analyzed in this study to explore possible relationships between writing and relationship satisfaction.

The following discussion addresses findings related to the preliminary analysis and the two research questions proposed in this study. This chapter will describe possible implications of the findings, limitations of the study, and potential directions for future research and interventions.

\section{Research Questions}

\section{Preliminary Analyses}

Preliminary analyses helped examine the relationship between variables. Correlational relationships helped influence the process of variable inclusion in subsequent data analysis models. Frequency of daily communication was positively related to marital satisfaction for men and women. Dr. John Gottman has explained a possible reason for this association by explaining that happy couples frequently share in 
small moments. This shows that couples turn toward each other and include their partner in their life (Gottman \& Silver, 1999). The negative correlation between marital satisfaction and length of marriage was expected and supports previous research that has found similar results (Glenn, 1998; Vaillant \& Vaillant, 1993). Marital satisfaction for women was positively associated with first person plural pronouns and negatively associated with negative affect language use. This supports previous research that has found that men and women have different meanings of satisfaction in marriage (Acitelli \& Antonucci, 1994). This also implies that perceptions of togetherness and negativity in a relationship are more related to relationship satisfaction for women than for men.

\section{Research Question 1}

The focus of the first research question was to explore the relationship between pronoun use in writing (first person singular pronoun use and first person plural pronoun use) and marital satisfaction. Results suggested that individuals who use more first person plural pronouns (e.g., we) in their writing about their relationship were likely to report greater satisfaction in their relationship. This supports previous couple research that indicates that relationship perceptions are influenced by first person plural pronoun use (Agnew et al., 1998; Fitzsimons \& Kay, 2004). These previous studies had included couples who considered themselves in a partnered-romantic relationship but were not married. The current study adds to this body of research by looking specifically at married couples. Results are consistent across types of couples (dating, cohabiting, married, etc.). First person plural pronouns are important in relationships because they can symbolize a mental state of plural, collective perception of an individual in a 
relationship (Fitzsimons \& Kay, 2004). This finding is also linked to the way people express mutuality and cognitive room (Gottman \& Silver, 1999; Miller, 2012). High mutuality and cognitive room are concepts that show that individuals see themselves and their spouse as a part of a whole (the couple) more than as separate individuals. The feeling of a combined world and life helps couples to overcome stressful events and conflict. A high feeling of togetherness creates shared meanings, rituals, and goals that keep couples linked together (Gottman \& Silver, 1999). Implications of this finding could include the importance of individual feelings of being connected as a couple instead of independent from each other and how this is positively related to relationship satisfaction.

However, the use of first person singular pronouns (e.g., I) and marital satisfaction were not associated in the results from this study. The relationship with this result and previous research is unclear. Previous research concludes that more first person singular pronouns use is related to perceptions that the relationship is not as close and not as committed (Agnew et al., 1998). In other words, it was thought that there would be a negative correlation between first person singular pronoun use and marital satisfaction. It is possible that this was not found because the majority of the sample in this study was satisfied in their relationship and the use of negative affective language was minimal. The relationship between first personal singular pronouns and marital satisfaction could be stronger in a sample that included more distressed couples.

Although sex and length of marriage were included in the research questions, neither were significant so were not included in the final analyses for either question. 
Based on previous research, sex and length of marriage were considered variables that may influence significant differences in writing samples and marital satisfaction. In general, studies examining sex differences and marital satisfaction usually focus on differences in dealing with conflict, communication, stress, and problem-solving (Bradbury \& Karney, 2004; Katz \& Gottman, 1996; Schulz et al., 2004). Length of marriage research findings vary. Some studies find that marital satisfaction is most volatile in the first few years and then stabilizes (Mirecki et al., 2013; Raley \& Bumpass, 2003) while other studies explain that marital satisfaction steadily declines over time (Glenn, 1998; Vaillant \& Vaillant, 1993).

A possible reason for why the findings in this study were not consistent with previous studies is explained by Levenson and colleagues (1994). These authors explain that although there may be specific differences between men and women and between couples who have been married for different lengths of time, the biggest differences are seen between distressed and nondistressed couples. In the Levenson, Carstensen, and Gottman (1994) study, they found that distressed couples had smaller increases in positivity and more negative periods than nondistressed couples. This may help explain that because most of the couples in this study were nondistressed, sex and length of marriage were not significant. Although there is a need for more research regarding sex and length of marriage differences in writing samples of married couples, the results from this study indicate that sex and length of marriage are not statistically significant in answering the research questions for this study. 


\section{Research Question 2}

The second research question focused on the relationship between affective language use in writing (positive and negative emotion language) and marital satisfaction. Results indicated that individuals who used more positive language in their writing about his/her marital relationship also reported greater marital satisfaction. Individuals whose partners used more positive language in their writing were also more likely to report greater marital satisfaction. This is consistent with previous research that has found positive associations between positive affect and relationship satisfaction. Positive affect in relationships is related to more satisfaction in the relationship (Mattson et al., 2011) and has been seen to buffer the effects of poor problem-solving skills and high negativity (Bradbury \& Karney, 2004; Fincham \& Beach, 2010; Johnson et al., 2005). Previous findings and findings in the current study imply that positive affect in relationships may help provide a positive atmosphere for both partners. This could facilitate a place for sharing feelings, problem-solving, and enjoying time together as a couple. It could also be that positive affect helps negate the negative experiences and feelings that sometimes accompany relationships. Positive feelings can be so strong that they override negative feelings (Gottman \& Silver, 1999). Being positive about life may spillover into being positive about one's spouse and marriage and vice versa. These findings suggests that positive affect in a relationship, as reflected in writing samples, is important to relationship satisfaction for both partners.

While results indicate that positive affective language and marital satisfaction are positively related, the results do not indicate that there is a relationship between generally 
negative affective language and marital satisfaction. It was supposed that there would be a negative relationship between negative affective language use and marital satisfaction. This may be a finding that may again be due to the high number of nondistressed couples in the sample for this study. This also may indicate that positive affect is more strongly related to marital satisfaction than negative affect and could possibly act as a buffer for negative affect (Bradbury \& Karney, 2004; Fincham \& Beach, 2010; Johnson et al., 2005). More research is needed to uncover more about the relationship between negative affect and marital satisfaction.

To further understand the findings related to research question 2, a model was included with specific negative affective language categories (anxiety, anger, and sadness). Results from this model indicated that individuals who used more anger language in writing about the marital relationship also reported lower marital satisfaction. Anxiety and sadness were not significant for partner or actor. Renshaw, Blais, and Smith (2010) found similar results and concluded that anger in a relationship may have a unique influence on marital discord. The authors also concluded that the relationship between anger and relationship satisfaction may be different than other negative affective processes (anxiety and depression). The findings from this study support the finding that anger in relationships is an understudied concept. Renshaw and colleagues (2010) found that anger had significant negative actor and partner effects. This is not consistent with the results from the current study. The only statistically significant effects were actor effects and no statistically significant partner effects for anger affective language use were found. This highlights the potential negative impact anger can have on relationship 
satisfaction, even when considering other negative affective processes (anxiety and sadness).

The findings in this study give support for the importance of relationship perceptions (togetherness vs. independence) and positive affect in marriages. Individuals who perceive himself/herself and his/her spouse as a "greater whole" together (we-ness) are also more satisfied in their marriage. Positive affect in marriage writing samples are connected to higher relationship satisfaction for the individual who uses high positive affect and for his/her spouse. Positive affect is the only variable that was related to marital satisfaction for the individual and partner. This infers the important role positive affect can play for personal satisfaction as well as the satisfaction of a spouse. Anger is the only negative affect category that is negatively related to marital satisfaction.

This is a base for understanding the role of writing as a symbolic way of expressing relationship satisfaction. Although the relationship between first person plural pronouns and marital satisfaction is clear, it is not clear how and if first person singular pronouns is related to marital satisfaction. Positive affective language is associated to higher satisfaction for individuals and partners but the relationship between negative affective language, most specifically anger, and marital satisfaction is not understood. More research is needed to better understand how each of these variables could be symbols of marital satisfaction in writing and how these variables are more specifically related to marital satisfaction. More research is also needed to understand how these findings could potentially be influential for couple interventions and education. 


\section{Limitations}

The greatest limitation of this study was the use of a convenience sample. Although this is a limitation, this was also a novel, exploratory study. The nature of a convenience sample often results in a homogenous sample, which was true in this case. This limits the ability to generalize findings from this study beyond the sample of this study. The majority of this sample reported The Church of Jesus Christ of Latter-day Saints (LDS) as their religious affiliation. The LDS faith places a high focus on marriage and family (Holman, 1992). It is not known if that religious influence has an effect on how this sample would have written. Although this sample is very unique, this study provides a base to build on and more research could explore the findings by replicating the methods used with different populations and groups.

\section{Implications for Future Research}

This study provides clear implications for the use of symbolic interaction framework as a way to understand the symbolic nature of marital processes. Marital satisfaction is a symbolic construct that gives meaning to evaluating relationships. Through writing, individuals can portray perceptions about who they are and about his/her social world of relationships. This study supports perceptions of relationship "togetherness" is symbolically represented by using first person plural pronouns. This can represent how much couples feel that their lives are shared with their spouse. Positive affective language is a way individuals can reflect feelings about relationships in writing. Using positive words provides a way to symbolically see into the environment 
of a couple and their relationship. Implications from this study support Fitzsimons and Kay's (2004) conclusion that word choice communicates perceptions about relationships.

The current study provides important implications for future research and interventions. The exploratory nature of this study gives strength to the usefulness of writing as a method of providing insight into relationships. Specific findings help with future applied research with couple interventions. When individuals write using more first personal plural pronouns, they also report higher marital satisfaction. Future interventions could encourage reflection of shared experiences between partners. Reflecting on shared experiences could promote perceptions and feelings of mutuality and togetherness. Therapists and/or interventionist could also give writing assignments that encourage individuals to talk about experiences with partner using first person plural pronouns. Interventions could focus on individuals talking and thinking about his/her relationship as a place where both share in each other's experiences. By instructing individuals to write using "we" language in writing, couples perceptions of independence and togetherness in a relationship could change and mutuality could grow.

Positive affective language is important for marital satisfaction for actor and partner. It is important to note the partner effect of positive affective language. Positive affect is a potential area of intervention that influences both partners in a relationship. The potential of giving directions to write about positive experiences and aspects of a relationship could have relationship benefits, like Burton and King (2004) found with writing about positive experiences and physical health benefits. Future research could determine if teaching clients, participants, and/or students in family life education classes 
to focus on positive experiences (verbally and/or in writing) has positive causal effects for individuals and relationships.

There is potential benefit for individuals and couples by combining the findings about first personal plural pronouns and positive affective language. Interventionists and therapists could instruct couples to write about positive experiences with their spouse and focus on using "we" language. This would help understand the influence of the association between couple togetherness and positive experiences. An experimental design could examine the causal effects of different writing instructions such as instructions that focus on the use of first personal plural pronouns only, positive language instructions only, or a combined set of instructions.

There are implications for therapists, educators, and researchers regarding the finding that individuals who use more anger language report lower marital satisfaction. Anger could be different from anxiety or sadness in that it is often a secondary, not primary, emotion. A primary emotion is a basic and initial reaction to an experience or situation. Secondary emotions are reactions to primary emotions. Secondary emotions may serve as defenses against unwanted primary emotions. Thus, anger in relationships could be expressed when the primary emotion is hurt, pain, or shame (Pascual-Leone, Gillis, Singh, \& Andreescu, 2013). Interventionists and therapists should be aware of anger and the potential harm of anger in relationships (Renshaw et al., 2010) and intervene as needed. Future research could focus on basic understanding of when, where, and how anger influences relationships. 
Length of marriage and sex were originally included because of previous research that indicated that these variables may be important in understanding marital satisfaction. Previous studies have concluded that there are disparities between men and women reports and meanings of marital satisfaction (Acitelli \& Antonucci, 1994; Brock \& Lawrence, 2008). Previous research also indicates that marital satisfaction changes across time and with the length of marriage (Glenn, 1998; Mirecki et al., 2013; Vaillant \& Vaillant, 1993). In regard to these two variables, these results are not consistent with previous research. Although this should be replicated in other studies for future support, this finding suggests that future interventions do not need to necessarily adapt for sex or length of marriage. Interventions could potentially be of equal benefit to both men and women and to couples in relationships of varying lengths. More research is needed to fully understand this concept and to explore if this is also true of couples in various types of relationships (e.g., cohabiting).

This study provides the groundwork for understanding the importance of pronoun use and positive affect in relationships. It also gives merit to understanding marital relationships through a symbolic interaction framework lens. Replicating the methods in this study with different samples would be beneficial for generalizability and further understanding of the relationships between written language and relationship satisfaction. Future studies also could explore the causal relationships between how individuals use pronouns, positive affective language, and satisfaction in relationships.

Previous expressive writing research has primarily included hard copy, handwritten samples from participants (Baddeley \& Pennebaker, 2011; Burton \& King, 
2004; Lepore \& Greenberg, 2002; Slatcher \& Pennebaker, 2006; Warner et al., 2006). Although completing the writing exercise for this study was offered in a hard copy, all participants chose to complete the study online. This has several implications for future writing research. First, participants may prefer to write electronically. In this study, participants were instructed to use the method of writing that they felt they could most easily express themselves. With $100 \%$ of the participants using the online option of completion, future studies may consider providing an electronic option. Second, overall the findings from online participants were consistent with expectations. This supports the usefulness of online methods of collecting writing samples. Future studies could explore the similarities and differences between handwritten and typed writing samples. Third, participants who choose to write electronically could be different from participants who handwrite. It would be interesting to further study the demographics of participants who have a choice between writing electronically and writing by hand.

\section{Conclusion}

Despite limitations and the need for additional research, this study is an important exploratory study that contributes to existing writing and marital satisfaction research. This study analyzed if there are relationships between marital satisfaction and first personal pronoun and affective language use in writing samples. Findings reveal that there are significant relationships between how individuals and partners write about their relationship and marital satisfaction. These findings point toward some important future studies and potential interventions. It is hoped that future research will build on this 
study by replicating the findings. It is also hoped that more research will continue to analyze the relationship between writing and marital satisfaction and the potential for applied studies and interventions. This study has created a base for future research and interventions to explore the effectiveness of studying and understanding relationship processes and relationship improvement. 


\section{REFERENCES}

Acitelli, L. K., \& Antonucci, T. C. (1994). Gender differences in the link between marital support and satisfaction in older couples. Journal of Personality and Social Psychology, 67(4), 688-698. Doi: 10.1037/0022-3514.67.4.688

Agnew, C. R., Van Lange, P. M., Rusbult, C. E., \& Langston, C. A. (1998). Cognitive interdependence: Commitment and the mental representation of close relationships. Journal of Personality and Social Psychology, 74(4), 939-954. Doi: $10.1037 / 0022-3514.74 .4 .939$

Baddeley, J. L., \& Pennebaker, J. W. (2011). A postdeployment expressive writing intervention for military couples: A randomized controlled trial. Journal of Traumatic Stress, 24(5), 581-585. Doi: 10.1002/jts.20679

Berger, P., \& Kellner, H. (1994). Marriage and the construction of reality: An exercise in the microsociology of knowledge. In G. Handel \& G. G. Whitchurch (Eds.), The psychosocial interior of the family (4th ed.; pp. 19-36). Hawthorne, NY: Aldine de Gruyter.

Bhullar, N., Schutte, N. S., \& Malouff, J. M. (2011). Writing about satisfaction processes increases well-being. Individual Differences Research, 9(1), 22-32.

Bradbury, T. N., \& Karney, B. R. (2004). Understanding and altering the longitudinal course of marriage. Journal of Marriage and Family, 66(4), 862-879. Doi: 10.1111/j.0022-2445.2004.00059.x

Breuer, J., \& Freud, S. (1966). Studies on hysteria. New York, NY: Avon Books. (Original work published in 1895). 
Brock, R. L., \& Lawrence, E. (2008). A longitudinal investigation of stress spillover in marriage: Does spousal support adequacy buffer the effects? Journal of Family Psychology, 22(1), 11-20. Doi: 10.1037/0893-3200.22.1.11

Burns, K. C., \& Friedman, S. L. (2012). The benefits of emotional expression for math performance. Cognition and Emotion, 26(2), 245-251. Doi:

$10.1080 / 02699931.2011 .577564$

Burton, C. M., \& King, L. A. (2004). The health benefits of writing about intensely positive experiences. Journal of Research in Personality, 38(2), 150-163. Doi: $10.1016 / \mathrm{S} 0092-6566(03) 00058-8$

Campbell, R., \& Pennebaker, J. W. (2003). The secret life of pronouns: Flexibility in writing style and physical health. Psychological Science, 14(1), 60-65. Doi: $10.1111 / 1467-9280.01419$

Crain, W. (2011). Theories of development: Concepts and applications (6th ed.). Upper Saddle River, NJ: Prentice Hall.

Curtis, K. T., \& Ellison, C. G. (2002). Religious heterogamy and marital conflict findings from the national survey of families and households. Journal of Family Issues, 23(4), 551-576.

Deerwester, S. C., Dumais, S. T., Landauer, T. K., Furnas, G. W., \& Harshman, R. A. (1990). Indexing by latent semantic analysis. JASIS, 41(6), 391-407.

Esterling, B. A., Antoni, M. H., Fletcher, M., Margulies, S., \& Schneiderman, N. (1994). Emotional disclosure through writing or speaking modulates latent Epstein-Barr 
virus antibody titers. Journal of Consulting and Clinical Psychology, 62(1), 130140. Doi: 10.1037/0022-006X.62.1.130

Faul, F., Erdfelder, E., Buchner, A., \& Lang, A.-G. (2009). Statistical power analyses using $\mathrm{G}^{*}$ Power 3.1: Tests for correlation and regression analyses. Behavior Research Methods, 41, 1149-1160.

Fincham, F. D., \& Beach, S. H. (2010). Marriage in the new millennium: A decade in review. Journal of Marriage and Family, 72(3), 630-649. Doi: 10.1111/j.17413737.2010.00722.x

Fitzsimons, G. M., \& Kay, A. C. (2004). Language and interpersonal cognition: Causal effects of variations in pronoun usage on perceptions of closeness. Personality and Social Psychology Bulletin, 30(5), 547-557. Doi:

$10.1177 / 0146167203262852$

Foltz, P. W., Kintsch, W., \& Landauer, T. K. (1998). The measurement of textual coherence with latent semantic analysis. Discourse Processes, 25(2-3), 285-307.

Frattaroli, J., Thomas, M., \& Lyubomirsky, S. (2011). Opening up in the classroom: Effects of expressive writing on graduate school entrance exam performance. Emotion, 11(3), 691-696. Doi: 10.1037/a0022946

Funk, J. L., \& Rogge, R. D. (2007). Testing the ruler with item response theory: Increasing precision of measurement for relationship satisfaction with the couples satisfaction index. Journal of Family Psychology, 21(4), 572-583.

Gall, M. D., Gall, J. P., \& Borg, W. R. (2006). Education research: An introduction (8 ${ }^{\text {th }}$ Edition). Boston, MA: Pearson Education. 
Glenn, N. D. (1998). The course of marital success and failure in five American 10-year marriage cohorts. Journal of Marriage and the Family, 60(3), 569-576. Doi: $10.2307 / 353529$

Gonzales, A. L., Hancock, J. T., \& Pennebaker, J. W. (2010). Language style matching as a predictor of social dynamics in small groups. Communication Research, 37(1), 3-19.

Gottman, J., \& Silver, N. (1999). The seven principles for making marriage work. London, Great Britain: Orion Books.

Greenberg, L. S., \& Pascual-Leone, A. (2006). Emotion in psychotherapy: A practicefriendly research review. Journal of Clinical Psychology, 62(5), 611-630. Doi: $10.1002 /$ jclp. 20252

Hevey, D., Wilczkiewicz, E., \& Horgan, J. H. (2012). Type D moderates the effects of expressive writing on health-related quality of life (HRQOL) following myocardial infarction (MI). The Irish Journal of Psychology, 33(2-3), 107-114. Doi: $10.1080 / 03033910.2012 .708901$

Holman, T. B. (1992). Social and behavioral perspectives. In D. H. Ludlow (Ed.), Encyclopedia of Mormonism (pp. 855-857). New York, NY: Macmillan.

Ireland, M. E., Slatcher, R. B., Eastwick, P. W., Scissors, L. E., Finkel, E. J., \& Pennebaker, J. W. (2011). Language style matching predicts relationship initiation and stability. Psychological Science, 22(1), 39-44. Doi: $10.1177 / 0956797610392928$ 
Johnson, M. D., Cohan, C. L., Davila, J., Lawrence, E., Rogge, R. D., Karney, B. R.... Bradbury, T. N. (2005). Problem-solving skills and affective expressions as predictors of change in marital satisfaction. Journal of Consulting and Clinical Psychology, 73(1), 15-27.

Jordan, K. B. (1998). Programmed writing and therapy with conflictual couples. Journal of Family Psychotherapy, 9(2), 27-39. Doi: 10.1300/J085V09N02_03

Kahn, J. H., Tobin, R. M., Massey, A. E., \& Anderson, J. A. (2007). Measuring emotional expression with the linguistic inquiry and word count. The American Journal of Psychology, 263-286.

Kashy, D. A., \& Donnellan, M. B. (2012). Conceptual and methodological issues in the analysis of data from dyads and groups. In K. Deaux \& M. Snyder (Eds.), The Oxford handbook of personality and social psychology (pp. 209-238). New York, NY: Oxford University Press.

Katz, L., \& Gottman, J. M. (1996). Spillover effects of marital conflict: In search of parenting and coparenting mechanisms. New Directions for Child Development, 7457-7476.

Kenny, D. A., Kashy, D. A., \& Cook, W. L. (2006). Dyadic data analysis. New York, NY: Guilford.

LaRosa, R., \& Reitzes, D. C. (1993). Symbolic interactionism and family studies. In P. G. Boss, W. J. Doherty, R. LaRossa, W. R. Schumm, \& S. K. Steinmetz (Eds.), Sourcebook of family theories and methods: A contextual approach (pp. 135-166). New York, NY: Plenum. 
Lee, H. S., \& Cohn, L. D. (2010). Assessing coping strategies by analysing expressive writing samples. Stress and Health: Journal of the International Society for the Investigation of Stress, 26(3), 250-260. Doi: 10.1002/smi.1293

Lepore, S. J., \& Greenberg, M. A. (2002). Mending broken hearts: Effects of expressive writing on mood, cognitive processing, social adjustment and health following a relationship breakup. Psychology \& Health, 17(5), 547-560. Doi:

$10.1080 / 08870440290025768$

Lepore, S. J., \& Smyth, J. M. (2002). The writing cure: How expressive writing promotes health and emotional well-being. Washington, DC: American Psychological Association.

Levenson, R. W., Carstensen, L. L., \& Gottman, J. M. (1994). Influence of age and gender on affect, physiology, and their interrelations: A study of long-term marriages. Journal of Personality and Social Psychology, 67(1), 56-68. Doi: $10.1037 / 0022-3514.67 .1 .56$

Lumley, M. A., \& Provenzano, K. M. (2003). Stress management through written emotional disclosure improves academic performance among college students with physical symptoms. Journal of Educational Psychology, 95(3), 641-649. Doi: http://dx.doi.org/10.1037/0022-0663.95.3.641

Mattson, R. E., Frame, L. E., \& Johnson, M. D. (2011). Premarital affect as a predictor of postnuptial marital satisfaction. Personal Relationships, 18(4), 532-546. Doi: 10.1111/j.1475-6811.2010.01315.x

Miller, R. S. (2012). Intimate relationships (6th edition). Boston, MA: McGraw-Hill. 
Mirecki, R. M., Chou, J. L., Elliott, M., \& Schneider, C. M. (2013). What factors influence marital satisfaction? Differences between first and second marriages. Journal of Divorce \& Remarriage, 54(1), 78-93. Doi:

$10.1080 / 10502556.2012 .743831$

O’Connor, D. B., Hurling, R., Hendrickx, H., Osborne, G., Hall, J., Walklet, E. ...Wood, H. (2011). Effects of written emotional disclosure on implicit self-esteem and body image. British Journal of Health Psychology, 16(3), 488-501. Doi:

$10.1348 / 135910710 \times 523210$

Osborne, C., \& McLanahan, S. (2007). Partnership instability and child well-being. Journal of Marriage \& Family, 69(4), 1065-1083. Doi: 10.1111/j.17413737.2007.00431.x

Pascual-Leone, A., Gilles, P., Singh, T., \& Andreescu, C. A. (2013). Problem anger in psychotherapy: An emotion-focused perspective on hate, rage, and rejecting anger. Journal of Contemporary Psychotherapy, 43(2), 83-92. Doi: $10.1007 / \mathrm{s} 10879-012-9214-8$

Pennebaker, J. W. (1997). Writing about emotional experiences as a therapeutic process. Psychological Science, 8(3), 162-166. Doi: 10.1111/j.1467-9280.1997.tb00403.x Pennebaker, J. W., Chung, C. K., Ireland, M., Gonzales, A., \& Booth, R. J. (2007). The development and psychometric properties of LIWC2007. Austin, TX: LIWC.net.

Pennebaker, J. W., Francis, M. E., \& Booth, R. J. (2001). Linguistic inquiry and word count (LIWC): LIWC2001. Mahwah, NJ: Erlbaum. 
Pennebaker, J. W., \& King, L. A. (1999). Linguistic styles: Language use as an individual difference. Journal of Personality and Social Psychology, 77(6), 1296-1312. Doi: 10.1037/0022-3514.77.6.1296

Pennebaker, J. W., Mayne, T. J., \& Francis, M. E. (1997). Linguistic predictors of adaptive bereavement. Journal of Personality and Social Psychology, 72(4), 863871. Doi: 10.1037/0022-3514.72.4.863

Raley, R. K., \& Bumpass, L. (2003). The topography of the divorce plateau: Levels and trends in union stability in the United States after 1980. Demographic Research, 8, 245-260. Doi: 10.4054/DemRes.2003.8.8

Renshaw, K. D., Blais, R. K., \& Smith, T. W. (2010). Components of negative affectivity and marital satisfaction: The importance of actor and partner anger. Journal of Research in Personality, 44(3), 328-334. Doi: 10.1016/j.jrp.2010.03.005

Schulz, M. S., Cowan, P. A., Pape Cowan, C., \& Brennan, R. T. (2004). Coming home upset: Gender, marital satisfaction, and the daily spillover of workday experience into couple interactions. Journal of Family Psychology, 18(1), 250-263. Doi: $10.1037 / 0893-3200.18 .1 .250$

Sillars, A., Shellen, W., McIntosh, A., \& Pomegranate, M. (1997). Relational characteristics of language: Elaboration and differentiation in marital conversations. Western Journal of Communication, 61(4), 403-422. Doi:

$10.1080 / 10570319709374587$ 
Slatcher, R. B., \& Pennebaker, J. W. (2006). How do I love thee? Let me count the words: The social effects of expressive writing. Psychological Science, 17(8), 660-664. Doi: 10.1111/j.1467-9280.2006.01762.x

Smyth, J. M. (1998). Written emotional expression: Effect sizes, outcome types, and moderating variables. Journal of Consulting and Clinical Psychology, 66(1), 174184.

Smyth, J. M., Stone, A. A., Hurewitz, A., \& Kaell, A. (1999). Effects of writing about stressful experiences on symptom reduction in patients with asthma or rheumatoid arthritis: A randomized trial. Journal of the American Medical Association, 281(14), 1304-1309. Doi: 10.1001/jama.281.14.1304

Stephen, T. D. (1984). A symbolic exchange framework for the development of intimate relationships. Human Relations, 37(5), 393-408. Doi:

$10.1177 / 001872678403700503$

Tausczik, Y. R., \& Pennebaker, J. W. (2010). The psychological meaning of words: LIWC and computerized text analysis methods. Journal of Language and Social Psychology, 29(1), 24-54.

Tov, W., Ng, K., Lin, H., \& Qiu, L. (2013). Detecting well-being via computerized content analysis of brief diary entries. Psychological Assessment, 25(4), 10691078. Doi: $10.1037 / \mathrm{a} 0033007$

Vaillant, C. O., \& Vaillant, G. E. (1993). Is the U-curve of marital satisfaction an illusion? A 40-year study of marriage. Journal of Marriage and the Family, 55(1), 230-239. Doi: $10.2307 / 352971$ 
Vernon, G. M. (1974). Toward a symbolic interaction theory. Salt Lake City, UT: National Science Foundation.

Warner, L. J., Lumley, M. A., Casey, R. J., Pierantoni, W., Salazar, R., Zoratti, E. M. ...Simon, M. R. (2006). Health effects of written emotional disclosure in adolescents with asthma: A randomized, controlled trial. Journal of Pediatric Psychology, 31(6), 557-568. Doi: 10.1093/jpepsy/jsj048

White, J. M., \& Klein D. M. (2008). Family theories ( $3^{\text {rd }}$ ed.). Thousand Oaks, CA: Sage. 
APPENDICES 
APPENDIX A

Letter of Information 

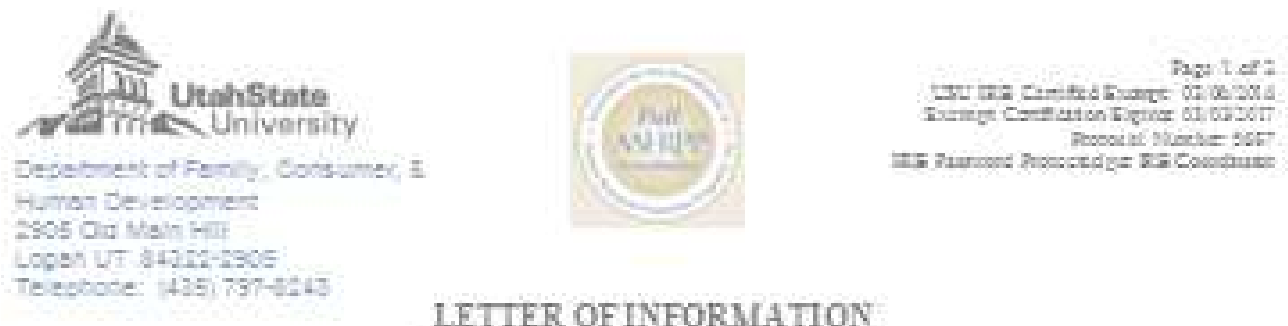

\section{LETIER OFINFORMATION \\ Writing and Marital Sarisfacrion}

Purpose. Dr Scot Allgo od in the Deparanent of Family Consumer and Faman Development at Utah State University and student researcher, Rachel Willians, are conducting a research study to find out more about writing and marital satiafaction. Writing is a tool for emotional processing. Although there is research on where and why writing can be beneficial, there is litle research that shows how writing could influence married couples. You have been asked to participate in this study because you are married and both you and your spouse have agred to participate. There will be approximately 60 total participant in this reseach project.

Procedures. If you agree to be in this ses arch study, you and your spouse will be asked to fill out separate questomaires about your merriage and write individually for 15-20 mimutar about your relationship. The time estimsted to complete the paticipation for this stuty is 30 mimtes. The questionnaire and witing exercise can be completed either on the computer (through an onlinesurvey provider) or in hard copy. In either case, wewill not atk for any identífying infornation

Risls. Particip ation in this rexeach study has minimal risk; however there may be potential rids involved tha could be distessing to you There is a risk that raxponding to some of the items may case distress. You nay slip over any item that you do not wish to answer. The questionnaire and writing exercise is intended to be retumed to the raxexchers without your spouse seeing it If your spouse does see your rasponses, you may experience distress, but carefilly following instructions will prevent that from happening Thes is a small risk of loss of confidentiality but we will take steps to rectace this risk

Benefits. The benefit of this research is that the researchers may leam nore about how writing influences marital satisfaction. The information gained though this study may bro aien lnowledge about therelationship between writing and marital satis faction including the potential usefulness of future marriage-based writing interventions. These benefits are not expected to influence participants directly but may have indirect benefits for participants and others in the funtre

Explanation and Offer to Aws wer Questions. The participation instructions explain this res mach study to you and hopefilly anavers your questions. If you have other questions or research-elated problems. you may sach (PI) Scot Allgood at (435) 797-1551(ccot alleo od âusueth) or Rachel Willians at (801) 941-6769 (achelbwilliams129encil com)

Voluntary Nature of Participation. Participation in this research is entirely vohnrary. Youmag refise to participate, refise to answer any quextions or withdraw at any time. If at any time you fol uncomfortable with the material prasented you may withdraw. You will only be withirawn from the research study if retumed materials are not filly conpleted and missing information is inportant to the study 


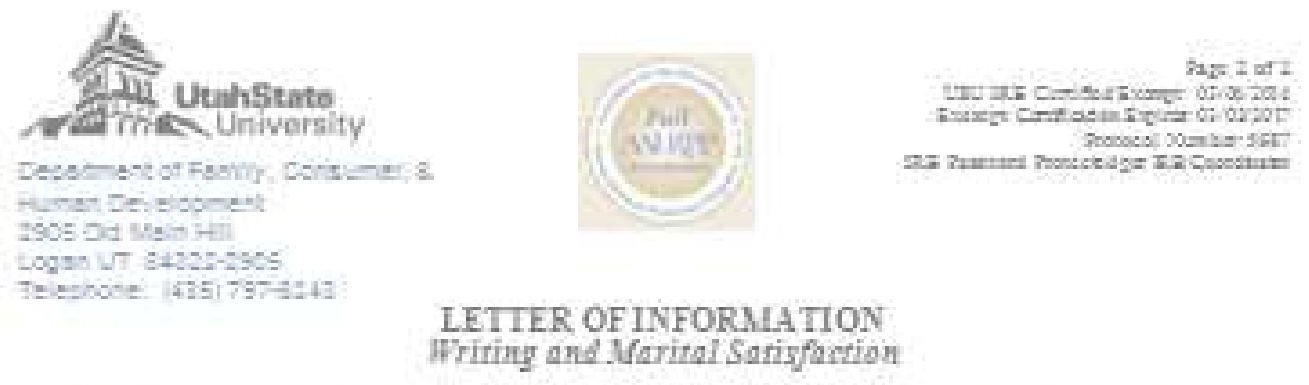

Confidentiality. There will beno personally identifying information asked on the questiomaire and wa ask that you do not include any information that specifically identifie you (name, address, etc) in your responses or the writing sample. Resexch records will be bept confidential, consistent with federal and state regulations. Only the investigator and student rexearcher will have access to the data which will be kept on an encrpplad, safe webs ite on a passw ord protected computer.

IRB A pproval Statement. The Instituiomal Review Bord for the protetion of human participants at Utah State University has app roved this research study. If you have any pertinent questions or concems about your rights or a research-elated injury, you may contact the IRB Administator at (435) 797-0567 or email in anvasu. If you have a concem or complaint about the raxexch and you would like to contact someone other than the research tean, you may contact the IRB Adninistrator to ob tain information or to offer input.

\section{Siguature of Resesrchers:}

Dr. Scot Allgood

Principal Investigator

(435-797-155i)

(scotailgood gusuedu)
Rachel Williams

Student Researcher

(001-941-0769)

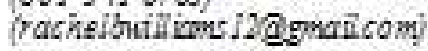


APPENDIX B

Information Survey 
Information Survey

1. Please enter the code found on the information card

2. What is your sex? (Circle one)

Male Female

3. What is your age?

4. Years of completed education (high school $=12$ )

5. What is your total household income?

Under $\$ 19,999$

$\$ 20,000$ to $\$ 39,999$

$\$ 40,000$ to $\$ 59,999$

$\$ 60,000$ to $\$ 79,999$

$\$ 80,000$ to $\$ 99,999$

Over $\$ 100,000$

6. How do you define your ethnicity? (Circle one)

Caucasian Latino/a Pacific Islander

African American Asian Other

7. How many years have you been married?

8. How many times have you been married?

9. How many children do you have? 
10. My outlook on life is based on my spiritual beliefs. Do you...

Strongly agree

Agree

Neither agree nor disagree

Disagree

Strongly disagree

Don't know

11. What is your religious preference (if any)? (Circle one)

LDS Catholic Protestant

None Non-denominational Other

12. On average, how often do you write in your journal? (Circle one)

Daily Weekly Monthly Yearly Never

13. How often do you and your spouse go on a date? (Circle one)

Daily Weekly Monthly Yearly Never

14. How often do you communicate with your spouse throughout the day (Includes face-toface, phone calls, texting, emails, chat, etc.) (Circle one)

0-3 times/day 4-7 times/day 8-10 times/day

11-14 times/day $\quad 15+$ times/day 
15. Please indicate the degree of happiness, all things considered, of your relationship.

$\begin{array}{ccccccc}\text { Extremely } & \text { Fairly } & \text { A Little } & \text { Happy } & \text { Very } & \text { Extremely } & \text { Perfect } \\ \text { Unhappy } & \text { Unhappy } & \text { Unhappy } & 3 & \text { Happy } & \text { Happy } & 6 \\ 0 & 1 & 2 & & 4 & 5 & \end{array}$

16. In general, how often do you think that things between you and your partner are going well?

$\begin{array}{llll}\text { All the time } & \begin{array}{l}\text { Most of the } \\ \text { time }\end{array} & \begin{array}{l}\text { More often Occasionally Rarely Never } \\ \text { than not }\end{array} & \end{array}$

\begin{tabular}{|c|c|c|c|c|c|}
\hline $\begin{array}{l}\text { Not } \\
\text { at all } \\
\text { True }\end{array}$ & $\begin{array}{l}\text { A } \\
\text { little } \\
\text { True }\end{array}$ & $\begin{array}{l}\text { Somewhat } \\
\text { True }\end{array}$ & $\begin{array}{l}\text { Mostly } \\
\text { True }\end{array}$ & $\begin{array}{l}\text { Almost } \\
\text { Completely } \\
\text { True }\end{array}$ & $\begin{array}{l}\text { Completely } \\
\text { True }\end{array}$ \\
\hline
\end{tabular}

17. Our relationship

is strong

18. My relationship with my partner makes me happy

19. I have a warm and comfortable relationship with my partner

20. I really feel like part of a team with my partner 
$\begin{array}{ccccc}\text { Not } & \text { A } & \text { Somewhat Mostly } & \begin{array}{c}\text { Almost } \\ \text { Completely }\end{array} & \text { Completely } \\ \text { at all little } & & & \end{array}$

21. How rewarding is your relationship with your partner?

22. How well does your partner meet your needs?

23. To what extent has your relationship met your original expectations?

24. In general, how satisfied are you with your relationship?

For each of the following items, select the answer that best describes how you feel about your relationship. Base your responses on your first impressions and immediate feelings about the item.

\begin{tabular}{|c|c|c|c|c|c|c|c|}
\hline 25. INTERESTING & 5 & 4 & 3 & 2 & 1 & 0 & BORING \\
\hline 26. BAD & 0 & 1 & 2 & 3 & 4 & 5 & GOOD \\
\hline 27. FULL & 5 & 4 & 3 & 2 & 1 & 0 & EMPTY \\
\hline 28. STURDY & 5 & 4 & 3 & 2 & 1 & 0 & FRAGILE \\
\hline 29. DISCOURAGING & 0 & 1 & 2 & 3 & 4 & 5 & HOPEFUL \\
\hline 30. ENJOYABLE & 5 & 4 & 3 & 2 & 1 & 0 & MISERABLE \\
\hline
\end{tabular}

USU students who recruit participants for this study will have his/her name entered into a drawing to receive a reward. If you were recruited by a USU student, please enter his/her name here. 